\title{
How Complex can be the Unimolecular Decomposition of a Simple Molecule? The Case of Acetylene. An Electron Impact and PIPECO Investigation
}

\author{
By R. Locht ${ }^{1}$ and Ch. Servais ${ }^{2}$ \\ ${ }^{1}$ Départment de Chimie Générale et de Chimie Physique, Institut de Chimie, Bât. B6, Université de Liège, Sart-Tilman par B-4000 Liège 1, \\ Belgium \\ ${ }^{2}$ Institut d'Astrophysique, Bât. El, Université de Liège, Avenue de Cointe, 5, B-4000 Liège, Belgium \\ Dedicated to Prof. Dr. H. Baumgärtel on the occasion of his 60th birthday
}

\begin{abstract}
The dissociative ionization of $\mathrm{C}_{2} \mathrm{H}_{2}, \mathrm{C}_{2} \mathrm{D}_{2}$ and $\mathrm{C}_{2} \mathrm{HD}$ is presented in this work. Excepting the $\mathrm{H}_{2}^{+}$ion formation, all dissociation channels are thoroughly investigated by electron impact. The translational energy distribution as a function of the impinging electron energy and the appearance energy as a function of the translational energy are measured for all fragment ions. KE versus AE diagrams are obtained and the isotope effect is examined. All observed thresholds are analyzed in detail and dissociation mechanisms are proposed. For the $\mathrm{C}_{2} \mathrm{H}^{+}$ion, the PIPECO technique has also been used. From these discussions the $\mathrm{H}-\mathrm{C}_{2} \mathrm{H}, \mathrm{HC} \equiv \mathrm{CH}$ and $\mathrm{H}-\mathrm{C}_{2}$ binding energy values are proposed, i.e. $5.33 \pm 0.23 \mathrm{eV}, 9.83 \pm 0.10 \mathrm{eV}$ and $5.44 \pm 0.40 \mathrm{eV}$ respectively. The fragmentation paths leading to $\mathrm{C}^{+}, \mathrm{CH}_{2}{ }^{+}$and $\mathrm{C}_{2}{ }^{+}$are discussed in terms of dissociation mechanisms involving the transient vinylidene structure of the molecular ion as an intermediate.
\end{abstract}

Keyword: Acetylene / Dissociation / Electroionization / Photoionization / Coincidence / Kinetic energy

Die dissoziative Ionisation von $\mathrm{C}_{2} \mathrm{H}_{2}, \mathrm{C}_{2} \mathrm{D}_{2}$ und $\mathrm{C}_{2} \mathrm{HD}$ wird in dieser Arbeit vorgestellt. Sâmtliche der dissoziativen Zerfallskanäle, bis auf die $\mathrm{H}_{2}{ }^{+}$-Bildung, wurden mit Hilfe der Elektronenstoßionisation untersucht. Für sâmtliche Fragmentionen wurde die Verteilung der Translationsenergie als Funktion der Energie der auftreffenden Elektronen sowie die Auftrittspotentiale als Funktion der Translationsenergie gemessen. KE-AEDiagramme werden ermittelt sowie Isotopeneffekte bestimmt. Die experimentellen Schwellenenergien werden im Detail analysiert, so da $\beta$ sich Dissoziationsmechanismen ableiten lassen. Zur Bestimmung der Eigenschaften des $\mathrm{C}_{2} \mathrm{H}^{+}$-Ions wurde die PEPICO-Technik verwendet. Aus den experimentellen Resultaten lassen sich die Bindungsenergien von $\mathrm{H}-\mathrm{C}_{2} \mathrm{H}, \mathrm{HC} \equiv \mathrm{CH}$ und $\mathrm{H}-\mathrm{C}_{2}$ ableiten, die 5,33 $\pm 0,23 \mathrm{eV}, 9,83 \pm 0,10 \mathrm{eV}, 5,44 \pm 0,40 \mathrm{eV}$ betragen. Die Bildung von $\mathrm{C}^{+}, \mathrm{CH}_{2}^{+}$sowie $\mathrm{C}_{2}^{+}$wird mit Hilfe eines Dissoziationsmechanismus diskutiert, der eine transiente Vinyliden-Struktur des intermediären Molekülions beinhaltet.

\section{INTRODUCTION}

The chemical reaction and the chemical reactivity have certainly been among the major scientific concerns of Professor H. Baumgärtel. One of the priority axis of his own research and that of his successive students has been the investigation of the unimolecular decomposition of molecular ions by almost all existing techniques. Since more than fifteen years these investigations were extended to molecular clusters. He also pioneered the use of new light sources for ionization, e.g. synchrotron (DESY, BESSY) and laser radiation.

The present contribution to the 60th birthday of Professor H. Baumgärtel is in this research line and a symbol of our already more than fifteen years old but still strong collaboration.

The investigation of acetylene has first been motivated by the scarcity of the data related to its dissociative ionization. On the other hand, it looks a simple system including both $\pi$ and $\sigma$ bonding. Formally, this molecule is also isoelectronic with $\mathrm{N}_{2}$, in which $\mathrm{CH}$ is the "separated atomic species" corresponding to the $\mathrm{N}$ atom. In the most recent past, the $\mathrm{H}-\mathrm{C}_{2} \mathrm{H}$ binding energy has been the subject of a long dispute in numerous papers [1]. The $\mathrm{HC} \equiv \mathrm{CH}$ bond could be carefully investigated. Finally, rearrangement ions, e.g. $\mathrm{CH}_{2}^{+}$, can be studied allowing us to examine the possible isomerisation of the acetylenic molecular ion into e.g. its vinylidenic isomer.

In the present contribution we gathered all the experimental material related to the dissociative ionization of this molecule obtained recently by electron impact and photoionization experiments. 


\section{EXPERIMENT}

Two experimental techniques were used in this work: an electroionization experiment, already described in detail elsewhere [2] and a photoion-photoelectron coincidence spectrometer recently built and described in a forthcoming publication [3]. Only the most salient features of these setups will briefly be described below.

By the impact of energy controlled electrons the ions produced in a Nier-type ion source are allowed to drift out of the ion chamber, are fo-cussed on the ion source exit hole, energy analyzed by a retarding lens and mass selected in a quadrupole mass spectrometer. The detected ion current is continuously scanned as a function of either the electron energy at fixed retarding potential settings $V_{R}$ or the retarding potential at fixed electron energy $E_{e}$. Both signals are electronically differentiated. Most of the experimental parameters are computer controlled.

In the photoion-photoelectron (PIPECO) experiment the gaseous sample is effusively introduced in an ion chamber. Perpendicular to the photoelectron-photoion optical axis, the light produced by a discharge lamp is introduced into the ion chamber through a capillary of $0.5 \mathrm{~mm}$ diameter. Photoions are extracted by a weak electric field $\left(100 \mathrm{mV} \cdot \mathrm{cm}^{-1}\right)$ and are focussed on the entrance hole of a quadrupole mass spectrometer. Coaxially, in the opposite direction to the ions, photoelectrons are extracted and analyzed in a retarding field spectrometer with a differential output, as designed by Lindau et al. [4]. Both the photoion source and photoelectron spectrometer are surrounded by two $\mu$-metal cylinders to cancel all external magnetic fields. A photoelectron energy resolution of $30 \mathrm{meV}$ is obtained in coincidence conditions. Photoion kinetic energy distributions are measured by a retarding potential analyzer and a HWHM of $30 \mathrm{meV}$ is obtained for translational energy distributions of molecular ions. The electron and ion detectors are 17-stage electron multipliers with 20 ns FWHM output pulses. The power supplies used to drive both the electron energy analyzer and the ion optics are programmable by IBM PC through an RS $232 \mathrm{I} / \mathrm{O}$ port.

The hardware and software for the data acquisition in time-of-flight (TOF), PIPECO-, photoion kinetic energy- and mass spectrum-measuring modes were developed and installed on a FPGA-based, home-made interface inserted in an IBM-PC slot. Additional external modules were built for TOF measurement and coincidence gates generation.

Both experiments are mounted in a vacuum vessel baked-out at about $250{ }^{\circ} \mathrm{C}$ to obtain an ultimate vacuum lower than $10^{-8}$ Torr. For the electron impact experiment a sample pressure of $10^{-6}$ Torr is used whereas in the photoionization experiment a sample pressure of $2 \times 10^{-5}$ Torr is used for photoelectron spectra and translational energy distribution measurements. For TOF- and coincidence measurements a pressure lower than $2 \times 10^{-6}$ Torr of acetylene is used for better coincidence statistics and to avoid ion molecule reactions.

The $\mathrm{C}_{2} \mathrm{H}_{2}$ sample, of $99.997 \%$ purity and mixed with $1 \%$ acetone in a high pressure cylinder, is used without further purification. Samples of 1 liter at 1 atm of $\mathrm{C}_{2} \mathrm{D}_{2}$ and $\mathrm{C}_{2} \mathrm{DH}$ are of 99 and 93 at $\%$ purity respectively and are exempt from acetone.

The maximum of the molecular ions translational energy distribution is used as the zero-energy calibration point for the kinetic energy scale. This reference is continuously recorded during the measurement of the ionization efficiency curves of the fragment ions by electron impact. In the photoionization experiment the same calibration point has been maintained.

In the electron impact experiment, the electron energy scale is calibrated by using the production of $\mathrm{N}_{2}{ }^{+}$ and $\mathrm{N}^{+}$from $\mathrm{N}_{2}$ at $15.581 \mathrm{eV}$ and $24.294 \mathrm{eV}$ respectively [5]. When m/e interference exists, e.g. $\mathrm{CD}^{+}$or $\mathrm{CH}_{2}^{+}$ and $\mathrm{N}^{+}$the ionization energy of $\mathrm{Ne}$ at $21.564 \mathrm{eV}$ [6] is used. In the PIPECO-experiment the photoelectron energy scale is calibrated by using the adiabatic ionization energy of $\mathrm{C}_{2} \mathrm{H}_{2}$ in the $\mathrm{X}^{2} \mathrm{II}_{\mathrm{u}}$ state at $11.403 \mathrm{eV}$ [7].

All the results and measurements presented in the following sections are the result of several independent experiments performed to ensure reproducibility and to increase the signal-to-noise ratio by summation of the signals. This allows us also to estimate correctly the error on the measurements. In the diagrams displayed in this work, straight lines are fit to the data by linear regression and the error on both the slope and extrapolation are calculated [8].

In the PIPECO-measurements, the TOF-distribution curves and the coincidence spectra are systematically smoothed to increase the signal-to-noise ratio. The smoothing procedure uses the Fourier 
transform incorporating appropriate filtering operators.

\section{EXPERIMENTAL RESULTS}

Excepting the $\mathrm{H}_{2}{ }^{+}$ion production, all the dissociative ionization channels occurring in $\mathrm{C}_{2} \mathrm{H}_{2}$ have been investigated. For sake of clarity in the presentation of the experimental results and their discussion in the following sections, the ionization channels were classified by (i) the $\mathrm{H}^{+}$and $\mathrm{C}_{2} \mathrm{H}^{+}$formation as leading to the estimation of the $\mathrm{H}-\mathrm{C}_{2} \mathrm{H}$ binding energy, (ii) the $\mathrm{CH}^{+}$formation giving access to the $\mathrm{HC} \equiv \mathrm{CH}$ binding energy measurement and (iii) the production of $\mathrm{C}^{+}, \mathrm{C}_{2}{ }^{+}$and $\mathrm{CH}_{2}{ }^{+}$which involves the vinylidenic ion as an intermediate.

\subsection{The $\mathrm{H}^{+}\left(\mathrm{D}^{+}\right)$and $\mathrm{C}_{2} \mathrm{H}^{+}\left(\mathrm{C}_{2} \mathrm{D}^{+}\right)$formation}

The $\mathrm{H}^{+}\left(\mathrm{D}^{+}\right)$dissociation channel has been investigated in $\mathrm{C}_{2} \mathrm{H}_{2}$ and $\mathrm{C}_{2} \mathrm{D}_{2}$ for two reasons: (i) to avoid any confusion of $\mathrm{H}^{+}$with other proton sources, e.g. $\mathrm{H}_{2} \mathrm{O}$ (from the background), acetone (present in the sample) and/or $\mathrm{H}_{2}$ produced by the possible thermolysis of hydrocarbons on the electron emitting filament, (ii) to investigate the isotope effect on the slope of the straight line in the kinetic energy (KE) versus appearance energy (AE) diagram. This isotope effect gives valuable informations on the dynamics of the considered dissociation channel.

The proton (deuteron) ion energy distribution has been measured for electron energies ranging from 22$99 \mathrm{eV}$. The first differentiated ionization efficiency curves of $\mathrm{H}^{+}\left(\mathrm{D}^{+}\right)$have been recorded between 15-45 eV electron energy for retarding potential settings increasing from 0.0-10.0 V. The KE versus AE plot resulting from these measurements is shown in Fig. 1 for $\mathrm{H}^{+}$.

Fig. 1: The $K E$ versus $A E$ diagram for $H^{+} / C_{2} H_{2}$ in the 17-42 $\mathrm{eV}$ electron energy range. The encircled numbers are used in the discussion (see text). The length of the error bars represent the standard deviation.

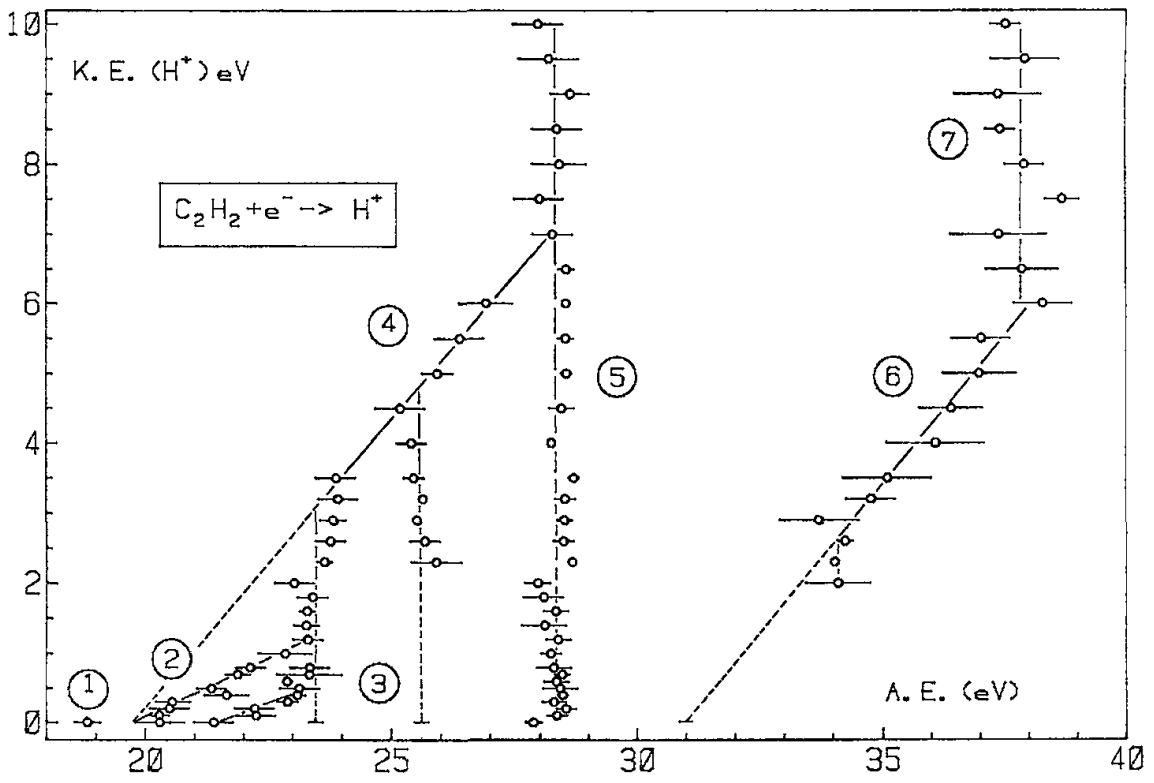

For $0.0 \mathrm{~V}$ retarding potential, this diagram clearly shows four threshold energies, i.e. at $18.8 \pm 0.2 \mathrm{eV}$, $20.3 \pm 0.4 \mathrm{eV}, 21.4 \pm 0.4 \mathrm{eV}$ and at $27.8 \pm 0.2 \mathrm{eV}$. The drawn straight lines $2-7$ are the result of linear regressions fit to the experimental data and four vertical lines are observed, i.e. at $23.5 \pm 0.3 \mathrm{eV}, 25.6 \pm 0.2 \mathrm{eV}, 28.4 \pm 0.2 \mathrm{eV}$ and at $37.4 \pm 0.5 \mathrm{eV}$. Fig. 2 shows the result of the same measurements on $\mathrm{D}^{+}$from $\mathrm{C}_{2} \mathrm{D}_{2}$ in a narrow retarding potential range of 0.0-1.6 V. In this diagram the results on $\mathrm{H}^{+}$from $\mathrm{C}_{2} \mathrm{H}_{2}$ are inserted for comparison. Appearance energies are observed at $19.3 \pm 0.1 \mathrm{eV}, 20.5 \pm 0.2$ and $21.4 \pm 0.2 \mathrm{eV}$. A vertical line is starting at $28.3 \pm 0.2 \mathrm{eV}$ up from $V_{R}=0.3 \mathrm{~V}$.

The ion translational energy distribution and the ionization efficiency of $\mathrm{C}_{2} \mathrm{H}^{+}\left(\mathrm{C}_{2} \mathrm{D}^{+}\right)$have been 
investigated. The KE distribution is quite similar to that of the molecular ion and the ionization efficiency could only be recorded for weak $(<50 \mathrm{mV})$ retarding potential settings (see Fig. 3). This result is expected, the $\mathrm{C}_{2} \mathrm{H}^{+}$ ion carrying $1 / 26$ part of the total excess kinetic energy, on the base of the momentum conservation law. Clearly two onset energies are observed, i.e. at $17.30 \pm 0.08 \mathrm{eV}$ and $18.27 \pm 0.11 \mathrm{eV}$ for $\mathrm{C}_{2} \mathrm{H}^{+}$and at $17.38 \pm 0.11 \mathrm{eV}$ and $18.45 \pm 0.26 \mathrm{eV}$ for $\mathrm{C}_{2} \mathrm{D}^{+}$.

The $\mathrm{C}_{2} \mathrm{H}^{+}$dissociation is the only channel which could be investigated by PIPECO. Though observed in the mass spectrum of $\mathrm{C}_{2} \mathrm{H}_{2}$ recorded at $54.8 \mathrm{~nm}$, the $\mathrm{C}_{2}{ }^{+}$ion could not be measured within a reasonable time. Fig. 4 shows the translational energy distribution observed at $58.4 \mathrm{~nm}$ and is compared to $\mathrm{C}_{2} \mathrm{H}_{2}{ }^{+}$in the same figure. No significant differences have to be mentioned. Closely related to the KE carried away by the ion, the maximum of the TOF-distribution of $\mathrm{C}_{2} \mathrm{H}^{+}$has been measured at $33 \mu \mathrm{s}$ as shown in Fig. 5 .

Fig. 2: The $K E$ versus $A E$ diagram for $D^{+} / C_{2} D_{2}$ in the 0.0-1.2 $V$ retarding potential range (full dots). The encircled numbers refer to the same processes observed for $\mathrm{H}^{+} / \mathrm{C}_{2} \mathrm{H}_{2}$ (open circles). The length of the error bars is equal to the standard deviation.

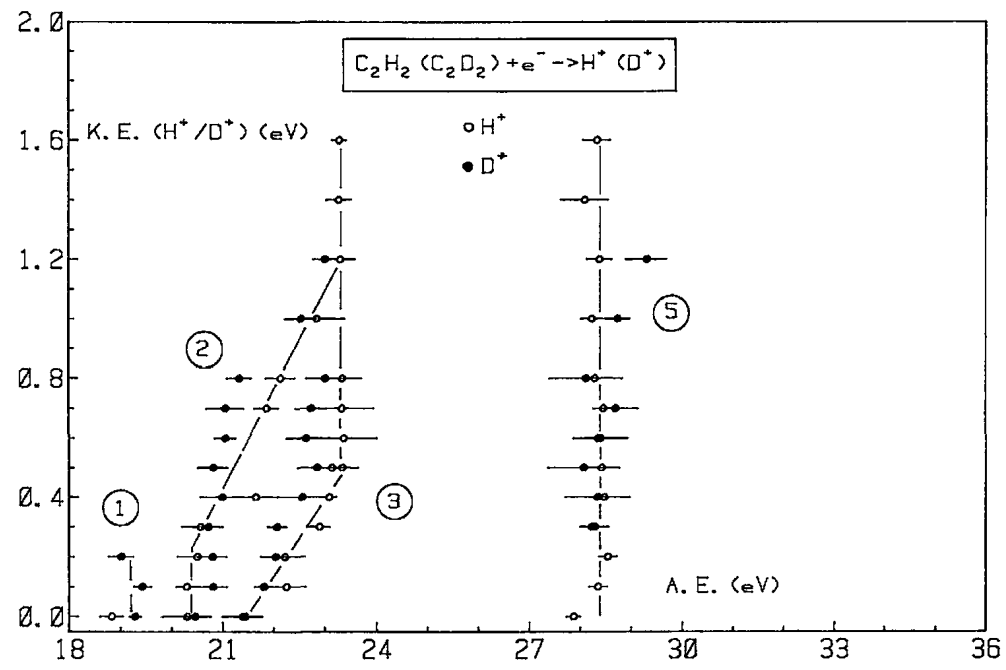

Fig. 3: The first differentiated ionization efficiency curve of $\mathrm{C}_{2} \mathrm{H}^{+} / \mathrm{C}_{2} \mathrm{H}_{2}$ and $\mathrm{C}_{2} \mathrm{D}^{+} / \mathrm{C}_{2} \mathrm{D}_{2}$ as observed without applying a retarding field. The vertical bars locate the average onset energies.

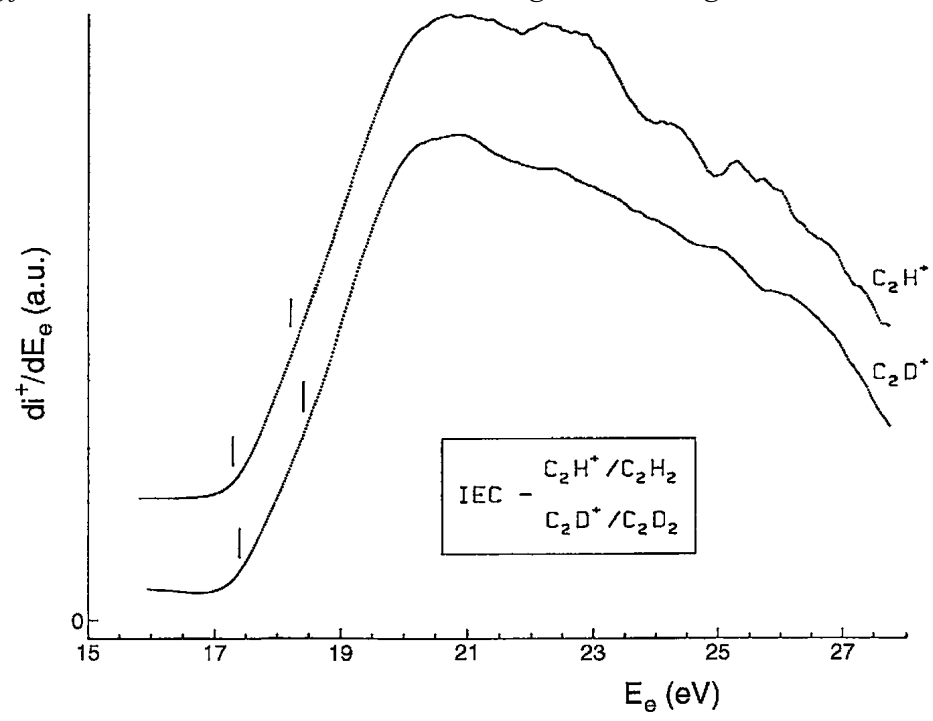


Fig. 4: The first differentiated retarding potential curves of the $\mathrm{C}_{2} \mathrm{H}^{+}$(full line) and $\mathrm{C}_{2} \mathrm{H}_{2}^{+}$(dotted line) ions recorded at $58.4 \mathrm{~nm}$.

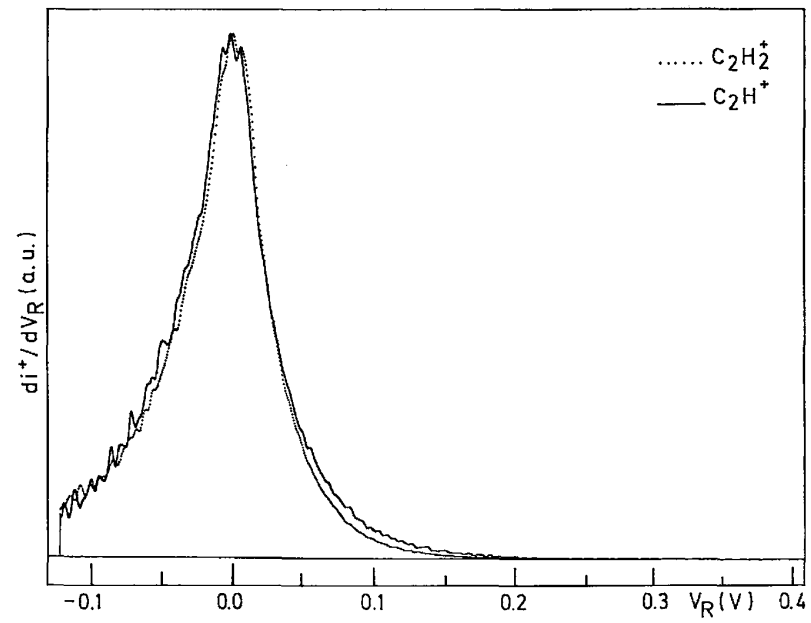

Fig. 5: TOF-spectrum of $\mathrm{C}_{2} \mathrm{H}_{2}{ }^{+}$and $\mathrm{C}_{2} \mathrm{H}^{+}$ions from $\mathrm{C}_{2} \mathrm{H}_{2}$ in coincidence with 2.5 eV photoelectrons (corresponding to the $\mathrm{B}^{2} \sum_{u}{ }^{+}$state of $\mathrm{C}_{2} \mathrm{H}_{2}{ }^{+}$). The signal is filtered by fast Fourier transform with a cos ${ }^{4}$ operator.

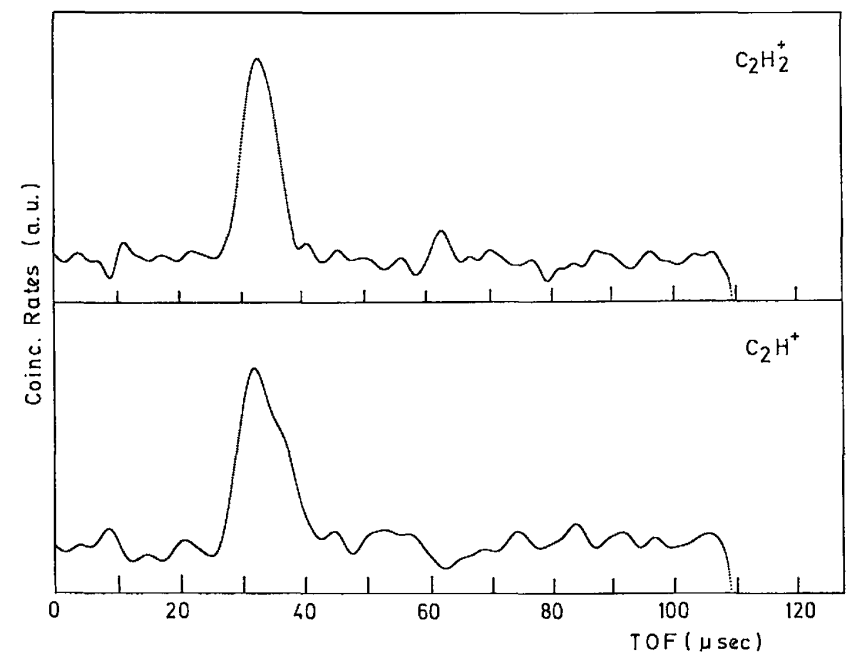

The maximum of the $\mathrm{C}_{2} \mathrm{H}_{2}{ }^{+}$-TOF distribution occurs at $33 \mu \mathrm{s}$, confirming the translational energy displayed in Fig. 6 for TOF $=33 \mu$ s, together with the photoelectron spectrum of $\mathrm{C}_{2} \mathrm{H}_{2}$ in the range of 16.2 $20.2 \mathrm{eV}$ ionization energy. Both coincidence spectra show structures strongly correlated with the photoelectron spectrum. The vibrational fine structure is clearly visible. It is important to mention that these spectra were recorded at low sample pressure, i.e. below $10^{-6}$ Torr. At higher pressures the mass spectrum shows the occurrence of $m / e=50$, assigned to $\mathrm{C}_{4} \mathrm{H}_{2}{ }^{+}$or $\left(\mathrm{C}_{2} \mathrm{H}\right)_{2}{ }^{+}$dimeric ions. At these pressures, $\mathrm{C}_{2} \mathrm{H}^{+}$has to be suspected to arise from these species.

\subsection{The $\mathrm{CH}^{+}\left(\mathrm{CD}^{+}\right)$formation}

Typical $\mathrm{CH}^{+}$ion kinetic energy distributions, as observed close to threshold, are shown in Fig. 7. At the threshold of $\mathrm{CH}^{+}$formation the maximum of the distribution is measured at $0.025 \pm 0.008 \mathrm{eV}$ and the FWHM is $120 \mathrm{meV}$. Above $21 \mathrm{eV}$ electron energy and up to $99 \mathrm{eV}$ new contributions are detected. 
Fig. 6: The photoelectron spectrum (a) of $\mathrm{C}_{2} \mathrm{H}_{2}$ as measured under coincidence conditions in the 16.2-20.2 eV ionization energy range. The assignment of the two vibronic bands are indicated. Photoion-photoelectron coincidence spectra of (b) $\mathrm{C}_{2} \mathrm{H}^{+}$and (c) $\mathrm{C}_{2} \mathrm{H}_{2}{ }^{+}$are shown in the corresponding energy range. The latter signals are filtered by fast Fourier transform. The arrow and dashed area show the onset for appearance of $\mathrm{C}_{2} \mathrm{H}^{+}$and the signal vanishing of $\mathrm{C}_{2} \mathrm{H}_{2}^{+}$and the associated uncertainty respectively.

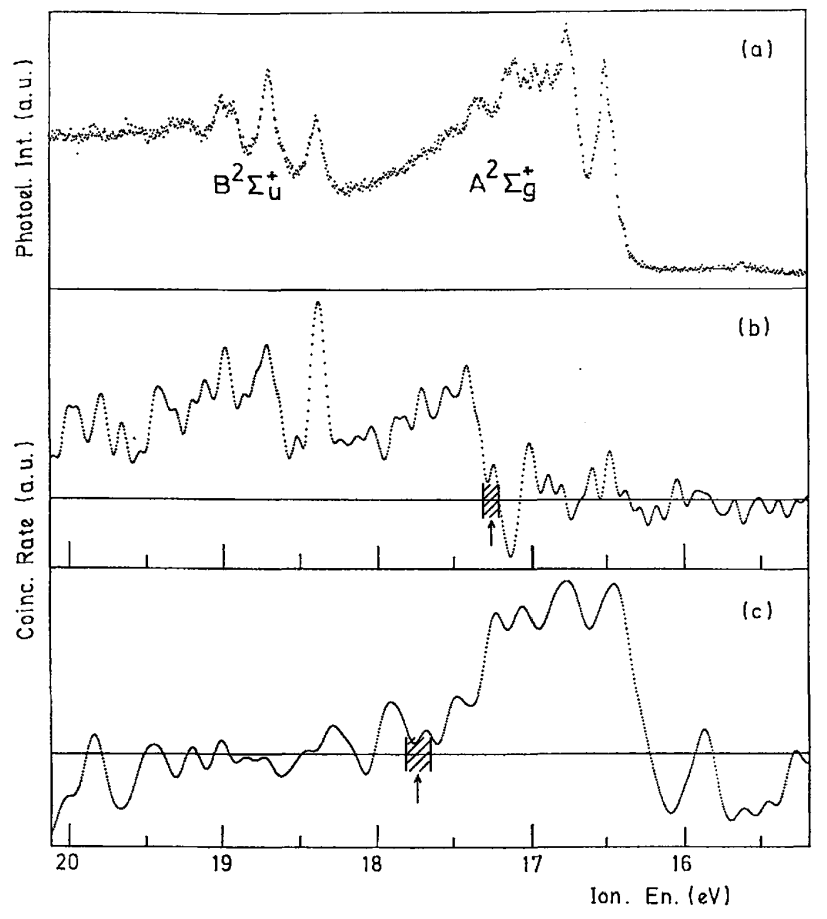

The first differentiated ionization efficiency curves of $\mathrm{CH}^{+}$from $\mathrm{C}_{2} \mathrm{H}_{2}$ have been recorded for increasing retarding potential settings. In the high electron energy range of the ionization efficiency an important contribution originates from doubly ionized $\mathrm{C}_{2} \mathrm{H}_{2}$ detected at $m / 2 e=13$. The $\left.\mathrm{C}_{2} \mathrm{H}\right|^{+}$production has been studied earlier [1]. The $\mathrm{KE}$ versus $\mathrm{AE}$ diagram obtained for $\mathrm{CH}^{+}$is displayed in Fig. 8 and shows twelve processes. Four onsets are measured when no retarding field is applied, i.e. at $20.83 \pm 0.05 \mathrm{eV}, 21.84 \pm 0.04 \mathrm{eV}, 24.9 \pm 0.03 \mathrm{eV}$ and $33.8 \pm 0.1 \mathrm{eV}$. This latter onset observed in the interval $V_{R}=0.0-0.1 \mathrm{~V}$ is ascribed to $\mathrm{C}_{2} \mathrm{H}_{2}{ }^{2+}$ for which the lowest onset energy is at $32.2 \pm 0.2 \mathrm{eV}$ and the second ionization energy (observed here) at $33.5 \pm 0.1 \mathrm{eV}$, as measured in $\mathrm{C}_{2} \mathrm{HD}[1]$.

The same measurements have been performed on $\mathrm{CD}^{+}$from $\mathrm{C}_{2} \mathrm{D}_{2}$ and the results for $V_{R}=0.0-1.4 \mathrm{~V}$ are shown in the KE versus AE diagram in Fig. 9. Dramatic isotope effects are observed and the data related to $\mathrm{CH}^{+}$ are inserted for comparison. For $\mathrm{CD}^{+}$onset energies are determined at $20.61 \pm 0.07 \mathrm{eV}, 21.26 \pm 0.08 \mathrm{eV}$ and $21.84 \pm 0.07 \mathrm{eV}$ in the electron energy range of $20-28 \mathrm{eV}$.

\subsection{The $\mathrm{C}^{+}, \mathrm{CH}_{2}^{+}$and $\mathrm{C}_{2}^{+}$formation}

The $\mathrm{C}^{+}, \mathrm{C}_{2}^{+}$and $\mathrm{CH}_{2}^{+}$dissociation channels have been studied by measuring both the translational energy distribution of these ions as a function of the electron energy $E_{\mathrm{e}}$ and the first derivative of the ionization efficiency as a function of the retarding potential $\mathrm{V}_{\mathrm{R}}$. The results obtained by this way are presented in the KE versus $\mathrm{AE}$ diagrams corresponding to these fragment ions. Fig. 10 shows such a plot related to $\mathrm{C}^{+}$where clearly six processes are observed. For $V_{R}=0.0 \mathrm{~V}$ threshold energies at $21.6 \pm 0.30 \mathrm{eV}, 22.24 \pm 0.20 \mathrm{eV}, 23.6 \pm 0.2 \mathrm{eV}$ and at $26.5 \pm 0.1 \mathrm{eV}$ are measured in the first differentiated ionization efficiency curve.

For the $\mathrm{C}_{2}^{+}$ion the translational energy distribution is similar to the thermal distribution observed for the molecular ion. This observation is expected, the $\mathrm{C}_{2}{ }^{+}$ion carrying only $2 / 26$ part of the total excess translational energy involved in the decomposition reaction. Moreover, its ionization efficiency curve could only be observed for retarding potential settings $V_{R}<0.05 \mathrm{~V}$. Threshold energies were measured at $18.44 \pm 0.07 \mathrm{eV}$, $19.58 \pm 0.14 \mathrm{eV}$ and $23.00 \pm 0.11 \mathrm{eV}$ successively in $\mathrm{C}_{2} \mathrm{H}_{2}$ and at $18.5 \pm 0.2 \mathrm{eV}, 19.5 \pm 0.3 \mathrm{eV}$ and at $23.12 \pm 0.12 \mathrm{eV}$ in $\mathrm{C}_{2} \mathrm{D}_{2}$. 
In spite of the precautions taken for keeping the background mass spectrum as low as possible, above the appearance energy of $\mathrm{N}^{+} / \mathrm{N}_{2}$, at $24.293 \mathrm{eV}$ [5], this species buries the $\mathrm{CH}_{2}^{+}$signal. Therefore the $\mathrm{KE}$ distribution and the appearance energy data are not considered above the $24.3 \mathrm{eV}$ energy limit. The data thus obtained are displayed in the KE versus AE plot shown in Fig. 11 where clearly two $\mathrm{CH}_{2}^{+}$producing processes are detected below $24.3 \mathrm{eV}$, i.e. $19.74 \pm 0.12 \mathrm{eV}$ and $21.10 \pm 0.20 \mathrm{eV}$. Together with the results related to $\mathrm{CH}_{2}^{+}$, those corresponding to $\mathrm{N}^{+} / \mathrm{N}_{2}$, investigated earlier [9], have been included. The excellent agreement between the two measurements convincingly confirms the detection of $\mathrm{N}^{+}$instead of $\mathrm{CH}_{2}^{+}$above $24.3 \mathrm{eV}$.

Fig. 7: The first differentiated retarding potential curves of $\mathrm{CH}^{+} / \mathrm{C}_{2} \mathrm{H}_{2}$ close below and above the appearance energy of this ion.

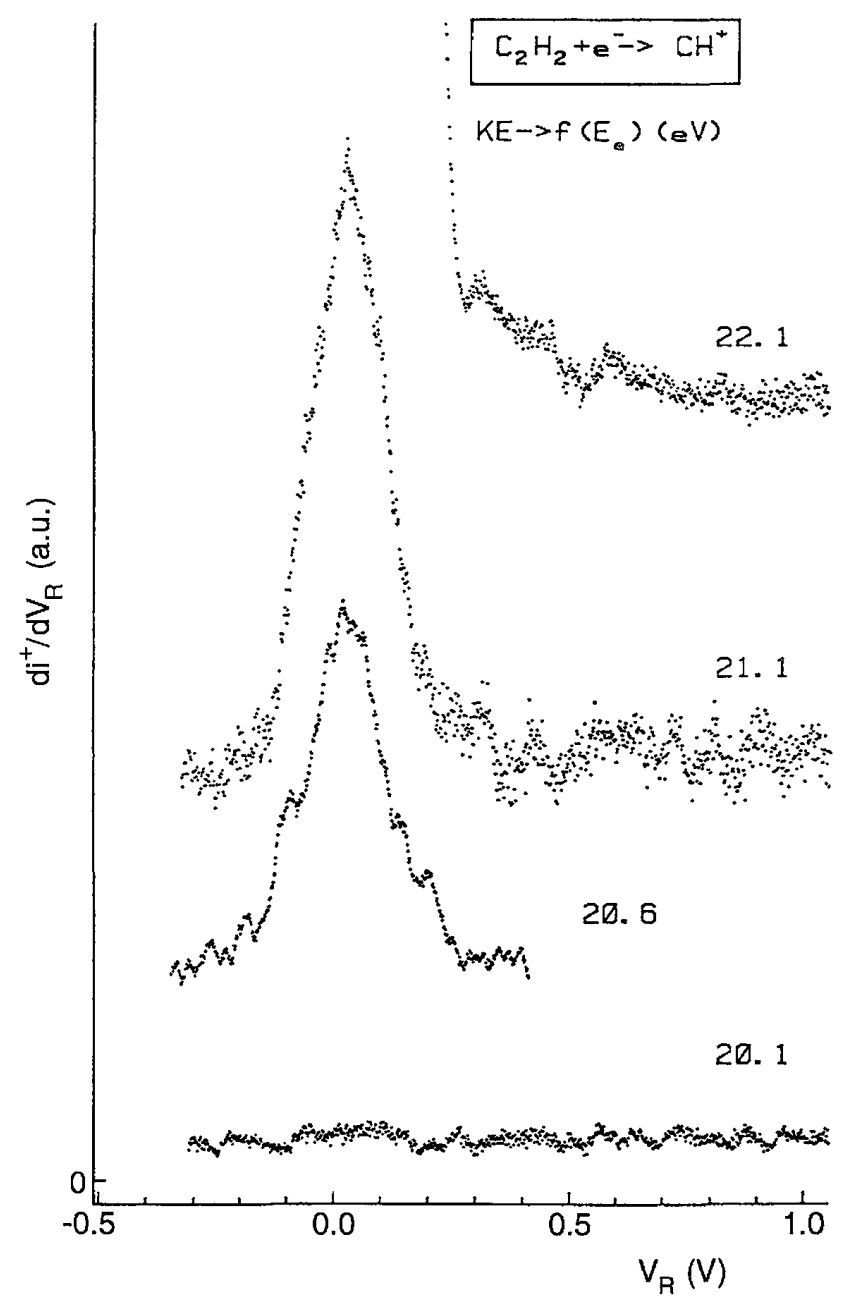

\section{DISCUSSION}

For the easiness and clarity in the following discussion, all the data used to calculate threshold energies for dissociative ionization processes giving rise to the ions to be considered in this work are gathered in Table 1 .

The $\mathrm{C}_{2} \mathrm{H}_{2}$ molecule belongs to the $\mathrm{D}_{\infty \mathrm{h}}$ symmetry group and the electronic configuration of the ground vibronic state $\mathrm{X}^{1} \sum_{\mathrm{g}}^{+}$is described by

$$
\left(1 \sigma_{\mathrm{g}}\right)^{2}\left(1 \sigma_{\mathrm{u}}\right)^{2}\left(2 \sigma_{\mathrm{g}}\right)^{2}\left(2 \sigma_{\mathrm{u}}\right)^{2}\left(3 \sigma_{\mathrm{g}}\right)^{2}\left(1 \pi_{\mathrm{u}}\right)^{4}
$$

Three ionic states are observed in the $\mathrm{He}(\mathrm{I})$-photoelectron spectrum. The adiabatic ionization energies are measured at $11.403 \mathrm{eV}\left(\mathrm{X}^{2} \Pi_{\mathrm{u}}\right), 16.297 \mathrm{eV}\left(\mathrm{A}^{2} \Sigma_{\mathrm{g}}^{+} / \mathrm{A}^{2} \mathrm{~A}_{\mathrm{g}}\right)$ and $18.391 \mathrm{eV}\left(\mathrm{B}^{2} \Sigma_{\mathrm{u}}^{+}\right)$[7]. The He(II)-photoelectron spectrum shows two more bands with a vertical ionization energy at $23.6 \mathrm{eV}$ and at $27.6 \mathrm{eV}$ successively [10]. The threshold photoelectron spectrum, obtained with synchrotron radiation [11], shows the existence of Rydberg 
states autoionizing to $\mathrm{C}_{2} \mathrm{H}_{2}^{+}\left(\mathrm{X}^{+} \Pi_{\mathrm{u}}\right)$ state and a structureless autoionizing state starting at $21.0 \mathrm{eV}$.

Fig. 8: The $\mathrm{KE}$ versus $\mathrm{AE}$ diagram of $\mathrm{CH}^{+} / \mathrm{C}_{2} \mathrm{H}_{2}$ in the 20-40 eV electron energy range. The encircled numbers are used for the discussion (see text). The length of the error bars is given by the standard deviation.
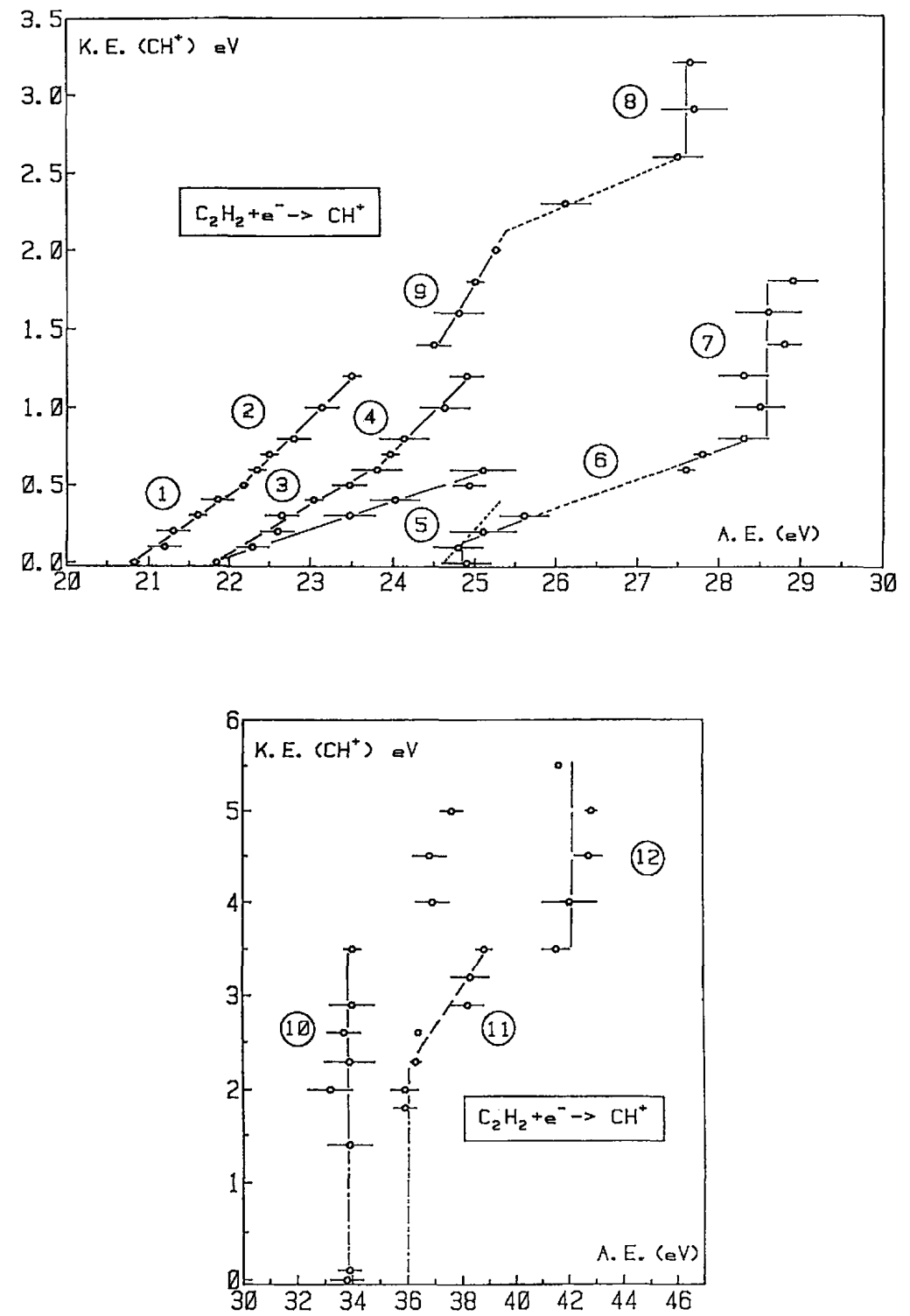

\subsection{The $\mathbf{H}^{+}\left(\mathrm{D}^{+}\right)$and $\mathrm{C}_{2} \mathrm{H}^{+}\left(\mathrm{C}_{2} \mathrm{D}^{+}\right)$dissociation channels}

\subsection{1}

The lowest onset for $\mathrm{H}^{+}$production from $\mathrm{C}_{2} \mathrm{H}_{2}$ is measured at $18.83 \pm 0.23 \mathrm{eV}$, whereas $\mathrm{D}^{+}$is observed at $19.2 \pm 0.2 \mathrm{eV}$. The former ion carries no translational energy, the latter is produced with $0.2 \mathrm{eV} \mathrm{KE}$ at threshold (see Fig. 2). Therefore, the $\mathrm{AE}\left(\mathrm{D}^{+}\right)_{\mathrm{KE}=0.0}=19.03 \pm 0.2 \mathrm{eV}$. The KE versus AE dependence of line (1) in Figs. 1 and 2 and the agreement within experimental error between both onsets warranties the proton is produced from $\mathrm{C}_{2} \mathrm{H}_{2}$ only. No other source has to be suspected at this onset.

The only electron impact determination is from Kusch et al. [18] reporting the lowest threshold of $\mathrm{H}^{+}$at $21.7 \pm 1.0 \mathrm{eV}$. More recently Shiromura et al. [19] measured the same onset at $19.35 \pm 0.05 \mathrm{eV}$ by photoionization 
using synchrotron radiation. The calculation of the lowest appearance energy for the reaction

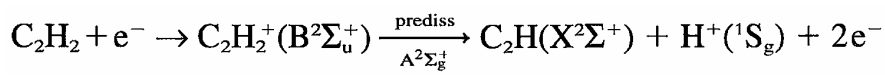

Fig. 9: The $K E$ versus $A E$ diagram of $C D^{+} / C_{2} D_{2}$ (full lines and full circles) restricted to the 0.0-1.5 eV translational energy range. For comparison the data related to $\mathrm{CH}^{+} / \mathrm{C}_{2} \mathrm{H}_{2}$ (dotted lines and empty circles) are introduced. Encircled numbers are used in the discussion (see text).

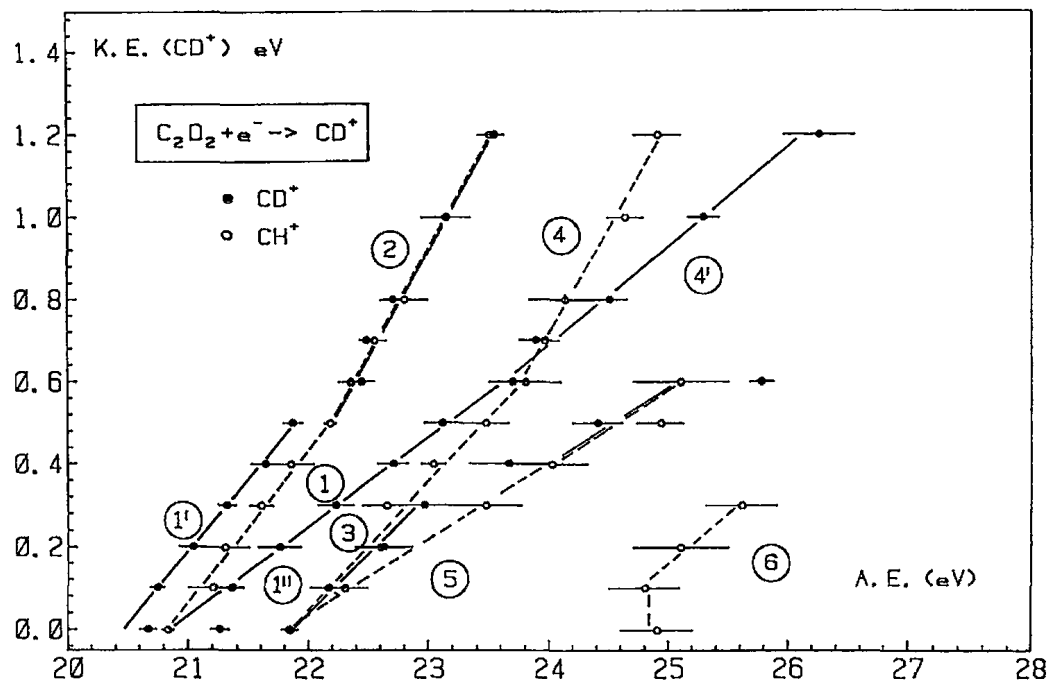

needs the value of the dissociation energy $\mathrm{D}\left(\mathrm{H}-\mathrm{C}_{2} \mathrm{H}\right)$. The present work provides (i) the translational energy at threshold, i.e. $\mathrm{KE}=0.0 \mathrm{eV}$ and (ii) the corresponding onset being $18.9 \pm 0.2 \mathrm{eV}$, i.e. the average of the appearance energy of $\mathrm{H}^{+}$and $\mathrm{D}^{+}$. If the radical $\mathrm{C}_{2} \mathrm{H}$ is supposed to be formed without internal energy a dissociation energy $D\left(H-C_{2} H\right)=5.33 \pm 0.20 \mathrm{eV}$ is derived (for the data used, see Table 1). The comparison of this value of the binding energy with that obtained by studying the counterpart reaction, i.e. $\mathrm{C}_{2} \mathrm{H}_{2}^{+} \rightarrow \mathrm{C}_{2} \mathrm{H}^{+}+\mathrm{H}$ and with previous determinations, will be presented in section 4.1.2.

Fig. 10: The $\mathrm{KE}$ versus $\mathrm{AE}$ diagram of $\mathrm{C}^{+} / \mathrm{C}_{2} \mathrm{H}_{2}$ in the 20-37 eV electron energy range. Encircled numbers are used in the discussion (see text).

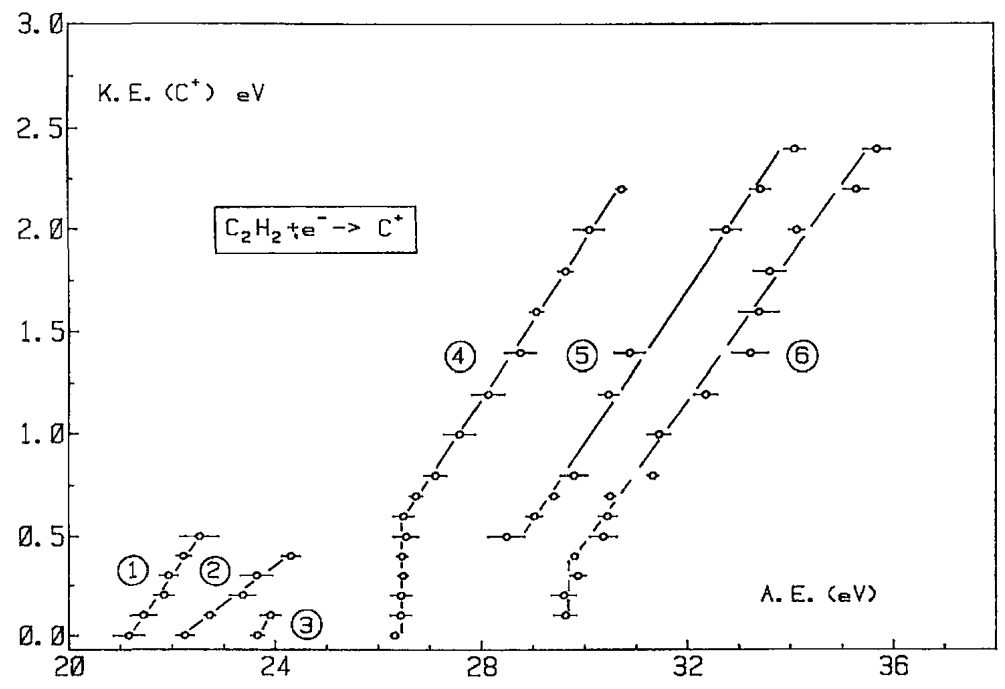


Fig. 11: The $\mathrm{KE}$ versus AE diagram of $\mathrm{CH}_{2}{ }^{+} / \mathrm{C}_{2} \mathrm{H}_{2}$ in the 18-29 eV electron energy range. Encircled numbers are used for the discussion (see text). The dashed straight line has a slope of 12/26=0.46. The full circles refer to the data on $N^{+} / N_{2}$ as measured in an earlier work [9].

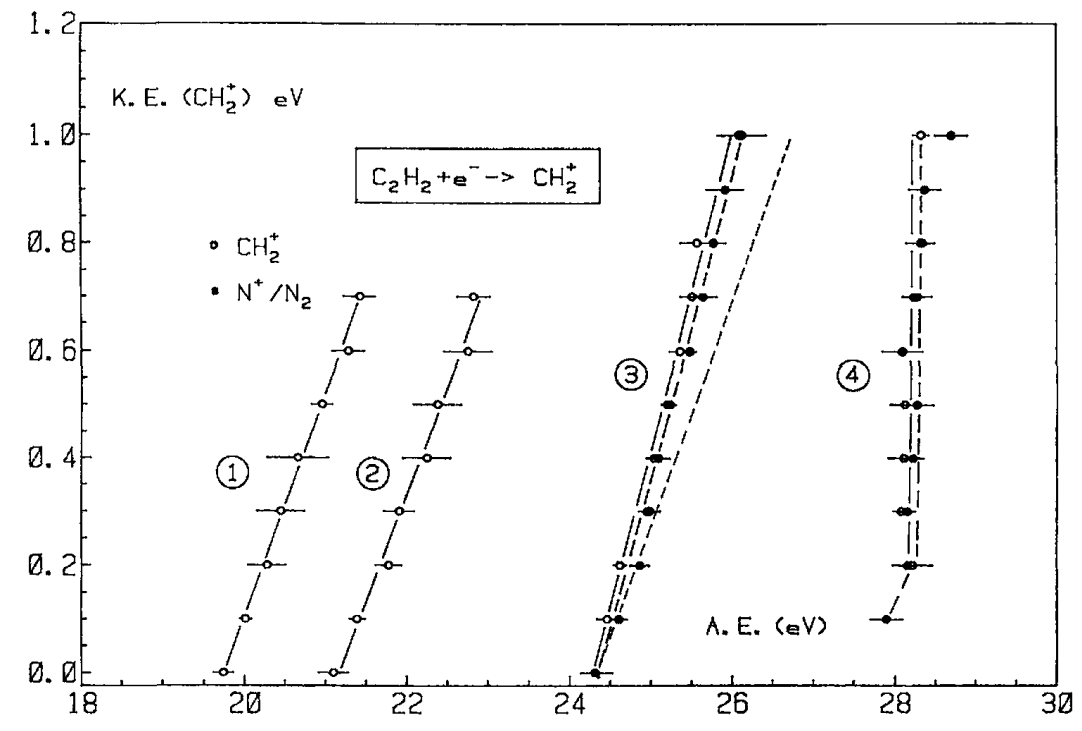

Table 1: Dissociation (D), ionization (IE), excitation (EE) energies and electron affinities (EA) (eV) of $\mathrm{C}_{2} \mathrm{H}_{2}$, $\mathrm{C}_{2} \mathrm{H}, \mathrm{CH}_{2}, \mathrm{C}_{2}, \mathrm{H}_{2}, \mathrm{CH}, \mathrm{C}$ and $\mathrm{H}$ used in this work ${ }^{a}$.

\begin{tabular}{cc}
\hline $\mathrm{D}\left(\mathrm{HC}_{2}-\mathrm{H}\right)=5.33 \pm 0.20^{\mathrm{b}}$ & $\mathrm{EE}(\mathrm{H}, n=2)=10.210$ \\
$\mathrm{D}(\mathrm{HO} \equiv \mathrm{CH})=9.83 \pm 0.10^{\mathrm{b}}$ & $\mathrm{EE}\left(\mathrm{C},{ }^{1} \mathrm{D}\right)=1.264$ \\
$\mathrm{D}\left(\mathrm{C}_{2}-\mathrm{H}\right)=4.85 \pm 0.31^{\mathrm{c}}$ & $\left(\mathrm{C},{ }^{1} \mathrm{~S}\right)=2.684$ \\
$\mathrm{D}(\mathrm{HC}-\mathrm{H}) \geq 4.33^{\mathrm{d}}$ & $\mathrm{EE}\left(\mathrm{C}^{+4},^{4} \mathrm{P}\right)=5.331$ \\
$\mathrm{D}(\mathrm{C} \equiv \mathrm{C})=6.21$ & $\left(\mathrm{C}^{+},{ }^{2} \mathrm{D}\right)=9.290$ \\
$\mathrm{D}(\mathrm{C}-\mathrm{H})=3.465^{\mathrm{e}}$ & $\mathrm{EE}\left(\mathrm{CH}, \mathrm{a}^{4} \Sigma^{-}\right)=0.724$ \\
$\mathrm{D}(\mathrm{H}-\mathrm{H})=4.476$ & $\left(\mathrm{~A}^{2} \Delta\right)=2.875^{\mathrm{e}}$ \\
$\mathrm{IE}(\mathrm{H})=13.598^{\mathrm{f}}$ & $\left(\mathrm{B}^{2} \Sigma^{-}\right)=3.229$ \\
$(\mathrm{C})=11.264^{\mathrm{f}}$ & $\left(\mathrm{C}^{2} \Sigma^{+}\right)=3.943$ \\
$(\mathrm{CH})=10.64^{\mathrm{e}}$ & $\mathrm{EE}\left(\mathrm{CH}^{+}, \mathrm{a}^{3} \Pi\right)=1.141$ \\
$\left(\mathrm{C}_{2}\right)=12.15^{\mathrm{e}}$ & $\left(\mathrm{A}^{1} \Pi\right)=2.898$ \\
$(\mathrm{CH})=10.396^{\mathrm{d}}$ & $\left(\mathrm{b}^{3} \Sigma^{-}\right)=4.736^{\mathrm{e}}$ \\
$\mathrm{EA}(\mathrm{H})=0.754^{\mathrm{g}}$ & $\left(\mathrm{B}^{1} \Delta\right)=6.513$ \\
$\left(\mathrm{C}_{2} \mathrm{H}\right)=2.969 \pm 0.010^{\mathrm{h}}$ & $\mathrm{EE}\left(\mathrm{C}_{2}^{+}, \mathrm{D}^{1} \Sigma_{\mathrm{u}}^{+}\right)=5.361^{\mathrm{e}}$ \\
& $\mathrm{EE}\left(\mathrm{CH}_{2}, \mathrm{a}^{1} \Delta_{1}\right)=0.394$ \\
& $\left(\mathrm{~b}^{1} \mathrm{~B}_{1}\right)=1.270$ \\
& $\left(\mathrm{~B}^{3} \Sigma_{\mathrm{u}}^{-}\right)=8.757$ \\
\hline
\end{tabular}

\footnotetext{
${ }^{\mathrm{a}} 1 \mathrm{eV}=23.060 \mathrm{kcal}^{\mathrm{mol}}{ }^{-1}=8065.73 \mathrm{~cm}^{-1}$.

${ }^{\mathrm{b}}$ As measured in this work.

${ }^{\mathrm{c}}$ Ref. [12]; ${ }^{\mathrm{d}}$ Ref. [13]; Ref. [14]; ${ }^{\mathrm{f}}$ Ref. [6]; ${ }^{\mathrm{g}}$ Ref. [15]; ${ }^{\mathrm{h}}$ Ref. [16]; ${ }^{\mathrm{i}}$ Ref. [17].
}

The vibronic state of both fragments in reaction 1 correlate with a $\mathrm{C}_{2} \mathrm{H}_{2}{ }^{+}\left({ }^{2} \Sigma^{+}\right)$state. The energy level of $18.9 \mathrm{eV}$, together with this symmetry, strongly suggests the $\mathrm{C}_{2} \mathrm{H}_{2}^{+}\left(\mathrm{A}^{2} \Sigma_{\mathrm{g}}{ }^{+}\right)$being a good candidate to be involved in process 1. On the other hand, the $\mathrm{C}_{2} \mathrm{H}_{2}{ }^{+}\left(\mathrm{B}^{2} \Sigma_{\mathrm{u}}{ }^{+}\right)$is populated by Franck-Condon transition in this energy range (see Fig. 6a). The $\mathrm{H}^{+}\left(\mathrm{D}^{+}\right)$ions would be produced by predissociation of the $\mathrm{B}^{2} \Sigma_{\mathrm{u}}^{+}$state through the $\mathrm{A}^{2} \Sigma_{\mathrm{g}}^{+}$state. The $C_{2} D_{2}$ photoelectron spectrum shows an unusually strong isotope effect on the vibrational structure. This could explain the drastic differences observed for $\mathrm{H}^{+}$and $\mathrm{D}^{+}$production at their lowest onset.

The second onset for $\mathrm{H}^{+}$is observed at $20.3 \pm 0.4 \mathrm{eV}$. It is the starting point of straight line (2) in Fig. 1. This linear regression fits the data with a correlation coefficient of 0.994 , the slope is $0.34 \pm 0.01$ and the 
extrapolation is $19.82 \pm 0.08 \mathrm{eV}$. For $\mathrm{D}^{+}$the corresponding onset is $20.4 \pm 0.12$ with a slope of $0.9 \pm 0.1$ with a correlation coefficient of 0.86 . The slope expected from the momentum conservation law is given by the ratios $25 / 26=0.96$ and $26 / 28=0.93$ for $\mathrm{H}^{+} / \mathrm{C}_{2} \mathrm{H}_{2}$ and $\mathrm{D}^{+} / \mathrm{C}_{2} \mathrm{D}_{2}$ respectively. The experimental and expected slopes agree fairly well in $\mathrm{C}_{2} \mathrm{D}_{2}$, whereas in $\mathrm{C}_{2} \mathrm{H}_{2}$ the discrepancy is significant. It indicates the partial (about $60 \%$ ) excess energy conversion into internal energy of the polyatomic fragment $\mathrm{C}_{2} \mathrm{H}$ [20]. The large difference in the dynamics of the reaction has very likely to be correlated with the strongly perturbed vibrational structure by isotopic substitution observed in $\mathrm{C}_{2} \mathrm{D}_{2}$.

The excess energy of $20.3( \pm 0.3)-18.9( \pm 0.2)=1.4+0.5 \mathrm{eV}$ has to be ascribed to vibronic excitation of the $\mathrm{C}_{2} \mathrm{H}$ radical. Several quantum mechanical [21-23] and spectroscopic [24-26] investigations of this radical have been reported. The lowest excited state should level at about $0.5 \mathrm{eV}$ above the ground state and should have the ${ }^{2} \sum$ multiplicity and symmetry. Though the discrepancy between this experiment and theoretical predictions, it could be suggested that at $20.1 \mathrm{eV}$ the reaction

$$
\mathrm{C}_{2} \mathrm{H}_{2}^{+*} \rightarrow \mathrm{C}_{2} \mathrm{H}\left(\mathrm{A}^{2} \Pi\right)+\mathrm{H}^{+}\left({ }^{1} \mathrm{~S}_{\mathrm{g}}\right)
$$

takes place, where the $\mathrm{C}_{2} \mathrm{H}$ radical would carry a certain amount of internal energy. The $\mathrm{H}^{+}\left(\mathrm{D}^{+}\right)$production very likely runs over a predissociation mechanism ascribed to the coupling of the $\mathrm{B}^{2} \mathrm{~A}_{1}, \mathrm{~A}^{2} \mathrm{~A}_{1}$ and $\mathrm{X}^{2} \mathrm{~A}_{1}$ states of $\mathrm{C}_{2} \mathrm{H}_{2}{ }^{+}$in the $\mathrm{C}_{2 \mathrm{~h}}$ configuration [7]. This would also be the origin of the reversed isotope effect observed on the slopes of the straight lines.

The straight line (3) in Figs. 1 and 2 gives threshold energies at $21.4 \pm 0.3 \mathrm{eV}$ and $21.46 \pm 0.22 \mathrm{eV}$ for $\mathrm{KE}$ $=0.0 \mathrm{eV}$ protons and deuterons respectively. The energy difference of $21.4( \pm 0.3)-18.9( \pm 0.2)=2.5 \pm 0.5 \mathrm{eV}$ is still too low to be assigned to the dissociation of the $\mathrm{H}-\mathrm{C}_{2}$ bond (see Table 1). It is also difficult to interpret these onsets because of lack of spectroscopic data related to $\mathrm{C}_{2} \mathrm{H}$. UV bands assigned to $\Sigma-\Sigma$ transitions at $3405 \AA$ have been reported [27]. Around $36000 \mathrm{~cm}^{1}$ emission bands were observed and tentatively ascribed to $\Pi-\Sigma$ transitions [26].

However, it is established that in the threshold photoelectron spectrum of $\mathrm{C}_{2} \mathrm{H}_{2}$ [11] a Rydberg state starts at $21.5 \mathrm{eV}$. Therefore, it could be proposed that the above mentioned processes should run over this autoionizing state giving rise to dissociative ionization.

Between 23 and $27 \mathrm{eV}$ the $\mathrm{KE}$ versus $\mathrm{AE}$ diagram unequivocally shows two processes, i.e. at $23.5 \pm 0.3$ $\mathrm{eV}$ and at $25.6 \pm 0.2 \mathrm{eV}$, converging to the same limit. The linear regression provides a limit at $\mathrm{KE}\left(\mathrm{H}^{+}\right)=0.0 \mathrm{eV}$ of $19.6 \pm 0.2 \mathrm{eV}$ and a slope of $0.86 \pm 0.02$. The phenomena observed at these energies have to run over ionic hypersurfaces of $\mathrm{C}_{2} \mathrm{H}_{2}^{+}$identified as $\Sigma^{+}$states in the He(II)- [28], TPES- [11] and X-ray photoelectron spectra [29]. These $\Sigma^{+}$states are described [30] as repulsive in the $\mathrm{H}-\mathrm{C}_{2} \mathrm{H}$ reaction coordinate in the Franck-Condon region and will provide protons carrying large amounts of translational energy.

The results of the foregoing discussion have been schematically represented in a two dimensional potential energy diagram displayed in Fig. 12 for the $\mathrm{H}-\mathrm{C}_{2} \mathrm{H}$ reaction coordinate.

The vertical line (5) reveals high energy protons produced both by $\mathrm{C}_{2} \mathrm{H}_{2}$ and by acetone present in the sample. Fig. 2 related to $\mathrm{C}_{2} \mathrm{D}_{2}$ (acetone-free) disentangles the part coming from acetylene and is limited to the 0.0-1.2 eV kinetic energy range. For these protons, at the threshold measured at $28.3 \pm 0.2 \mathrm{eV}$ the energy balance based on these data provides an $\mathrm{AE}_{\mathrm{KE}=0.0}\left(\mathrm{D}^{+}\right)=27.0 \pm 0.2 \mathrm{eV}$ and should correspond very likely to the reaction

$$
\mathrm{C}_{2} \mathrm{H}_{2}+\mathrm{e}^{-} \rightarrow \mathrm{C}_{2} \mathrm{H}_{2}^{+}\left({ }^{2} \Sigma^{+}\right) \rightarrow \mathrm{CH}\left(\mathrm{X}^{2} \Sigma\right)+\mathrm{C}\left({ }^{3} \mathrm{P}\right)+\mathrm{H}^{+}\left({ }^{1} \mathrm{~S}_{\mathrm{g}}\right)+2 \mathrm{e}^{-}
$$

which should run over repulsive ${ }^{2} \Sigma^{+}$hypersurfaces [30].

After an energy gap of $4 \mathrm{eV}$, several processes are observed between 34 and $40 \mathrm{eV}$. The vertical line at $34.1 \pm 0.4 \mathrm{eV}$ and the straight line extending up to $37.4 \pm 0.5 \mathrm{eV}$ should correspond to the decomposition of the doubly ionized molecular ion by "Coulomb explosion". Double ionization energies of $\mathrm{C}_{2} \mathrm{H}_{2}$ were determined experimentally by several methods [1,31], i.e. at $34.6 \pm 0.4 \mathrm{eV}$ [1] and at $37.9 \pm 0.4 \mathrm{eV}$ [31]. The latter onset being not detected in the $\mathrm{C}_{2} \mathrm{H}_{2}{ }^{2+}$ ionization efficiency, this should indicate that this state is dissociative in the FranckCondon region. The proton producing reaction should be 


$$
\mathrm{C}_{2} \mathrm{H}_{2}+\mathrm{e}^{-} \rightarrow \mathrm{C}_{2} \mathrm{H}_{2}^{2+}\left({ }^{3} \Pi / \Sigma^{3} \Sigma^{-}\right) \rightarrow \mathrm{C}_{2} \mathrm{H}^{+}\left(\mathrm{X}^{3} \Pi / \mathrm{A}^{3} \Sigma^{-}\right)+\mathrm{H}^{+}\left({ }^{1} \mathrm{~S}_{\mathrm{g}}\right)+3 \mathrm{e}^{-} \text {. }
$$

Fig. 12: Tentative schematic potential energy diagrams of $\mathrm{C}_{2} \mathrm{H}_{2}{ }^{+}$along the $\mathrm{H}-\mathrm{C}_{2} \mathrm{H}$ and the $\mathrm{HC} \equiv \mathrm{CH}$ reaction coordinates. The areas shaded by horizontal lines define the well depth observed in the He(I) photoelectron spectrum. Dashed lines locate the experimental data and the results from the discussion about $\mathrm{H}^{+}, \mathrm{C}_{2} \mathrm{H}^{+}$and $\mathrm{CH}^{+}$fragments production.

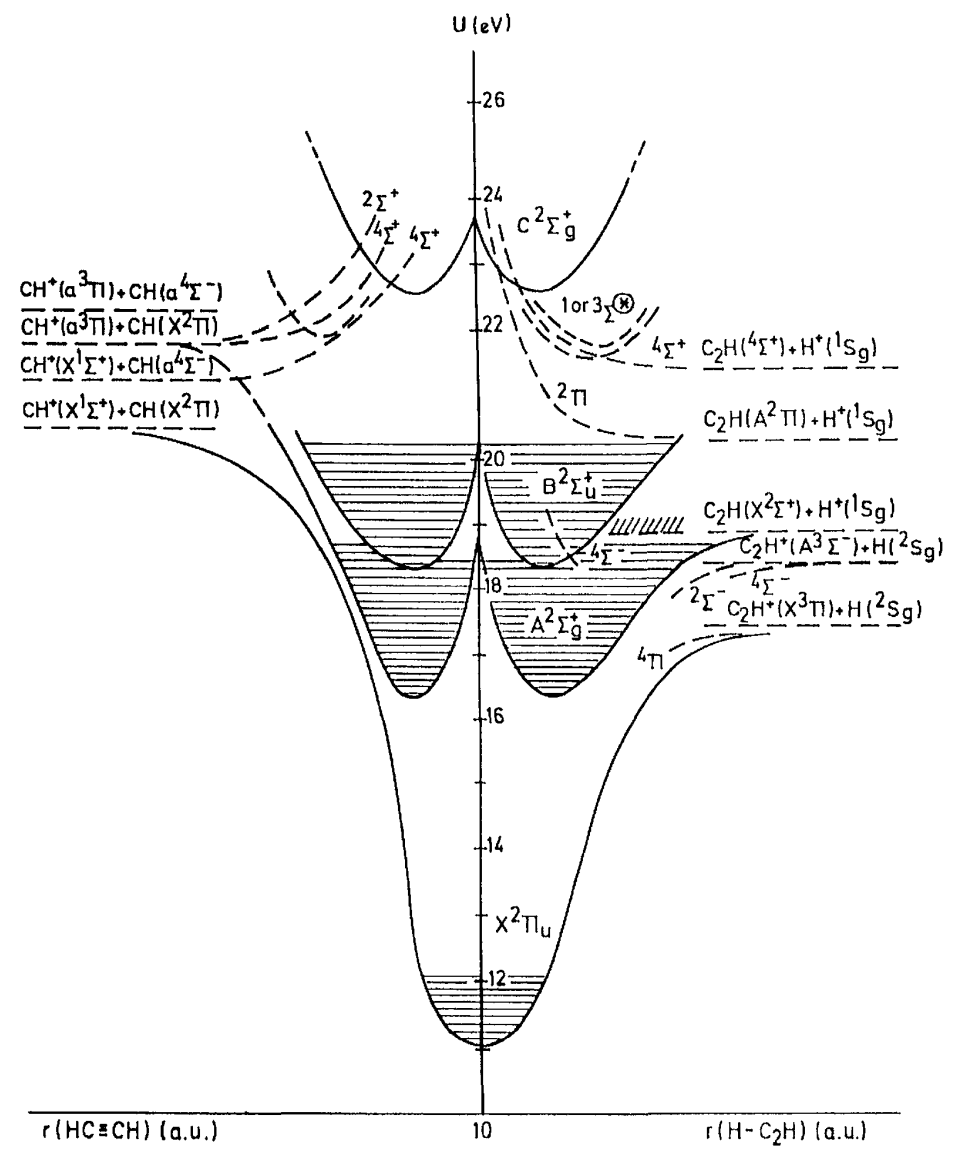

From an obvious energy balance, process (7) in Fig. 1 at $37.4 \pm 0.4 \mathrm{eV}$ should involve superexcited states of $\mathrm{C}_{2} \mathrm{H}_{2}^{+}$lying in the double ionization continuum.

\subsection{2}

As mentioned in section 3, the $\mathrm{C}_{2} \mathrm{H}^{+}$ion could only be observed when no retarding potential is applied. This means that the ion carries less than $10 \mathrm{meV}$ translational energy, i.e. $260 \mathrm{meV}$ in terms of total translational energy. This is shown to be the case also with $21.22 \mathrm{eV}$ photons (see Fig. 4).

The first observed onset for $\mathrm{C}_{2} \mathrm{H}^{+}$and $\mathrm{C}_{2} \mathrm{D}^{+}$is measured at $17.30 \pm 0.08 \mathrm{eV}$ and $17.38 \pm 0.11 \mathrm{eV}$ respectively (see Fig. 3). This is in very good agreement with most of the earlier electron impact and mass spectrometric photoionization experiments reported up-to-date [1]. However, Hayaishi et al. [32] and Ono and $\mathrm{Ng}$ [33] mention the lowest appearance energy to be $16.8 \pm 0.1 \mathrm{eV}$ and $16.79 \pm 0.03 \mathrm{eV}$ respectively. Recently ZEKE-PIPECO [34] and threshold PEPICO [35] works agree by measuring an onset at $17.36 \pm 0.01 \mathrm{eV}$ and $17.44 \pm 0.01 \mathrm{eV}$. The second onset determined in this work, i.e. at $18.27 \pm 0.10 \mathrm{eV}$ and $18.45 \pm 0.26 \mathrm{eV}$ in $\mathrm{C}_{2} \mathrm{H}_{2}$ and $\mathrm{C}_{2} \mathrm{D}_{2}$ respectively, has never been reported earlier.

Concerning the first onset of $\mathrm{C}_{2} \mathrm{H}^{+}$at $16.8 \mathrm{eV}$, it has to be pointed out that if there is good agreement for 
the energy, large discrepancies for the relative cross section have to be mentioned. Relative intensity differences of one order of magnitude are observed. In their electron impact work Plessis and Marmet [36] had to amplify the $\mathrm{C}_{2} \mathrm{H}^{+}$signal by 5000 to observe the onset at $16.7 \mathrm{eV}$. The main difference between these experiments [32, 33, $36]$ is the sample pressure. As mentioned in section 2, the present measurements were performed below $10^{-6}$ Torn In these conditions the $\mathrm{C}_{4} \mathrm{H}_{2}{ }^{+}$signal at $m / e=50$ is negligible. The present electron impact experiments are also carried out in these conditions. The $\mathrm{C}_{4} \mathrm{H}_{2}{ }^{+}$has to be suspected as the source of $\mathrm{C}_{2} \mathrm{H}^{+}$ions below $17.3 \mathrm{eV}$.

The lowest energetic process producing $\mathrm{C}_{2} \mathrm{H}^{+}$and $\mathrm{H}$ in their ground state through the dissociative ionization reaction of $\mathrm{C}_{2} \mathrm{H}_{2}$ should be

$$
\mathrm{C}_{2} \mathrm{H}_{2}+\mathrm{e}^{-}(h v) \rightarrow \mathrm{C}_{2} \mathrm{H}_{2}^{+}\left(\mathrm{A}^{2} \mathrm{~A}_{\mathrm{g}}\right) \underset{\mathrm{x}^{2} \Pi}{\stackrel{\text { prediss }}{\longrightarrow}} \mathrm{C}_{2} \mathrm{H}^{+}\left(\mathrm{X}^{3} \Pi\right)+\mathrm{H}\left({ }^{2} \mathrm{~S}_{\mathrm{g}}\right)+(2) \mathrm{e}^{-}
$$

The calculation of the appearance energy of $\mathrm{C}_{2} \mathrm{H}^{+}$through reaction 5 would need (i) the $\mathrm{H}-\mathrm{C}_{2} \mathrm{H}$ binding energy and (ii) the adiabatic ionization energy of the $\mathrm{C}_{2} \mathrm{H}$ radical. The translational energy involved in the process is less than $260 \mathrm{meV}$, as deduced from direct kinetic energy measurements. Supposing $\mathrm{C}_{2} \mathrm{H}^{+}$being formed without internal energy and using the experimental value of $\operatorname{IE}\left(\mathrm{C}_{2} \mathrm{H}\right)=11.6 \pm 0.5 \mathrm{eV}[37]$ and the binding energy $\mathrm{D}\left(\mathrm{H}-\mathrm{C}_{2} \mathrm{H}\right)=5.33 \pm 0.2 \mathrm{eV}$ proposed in this work (see section 4.1.1), an onset of $16.9 \pm 0.7 \mathrm{eV}$ is calculated for process 5 . This result is in very good agreement with the lowest and unreliable appearance energy obtained by photoionization measurements. However, considering the error limits, all the results are included in the $16.2-17.6 \mathrm{eV}$ energy range.

Both quantities, i.e. $\mathrm{IE}\left(\mathrm{C}_{2} \mathrm{H}\right)$ and $\mathrm{D}\left(\mathrm{H}-\mathrm{C}_{2} \mathrm{H}\right)$ are questionable. The latter has been discussed abundantly in the literature and ranges $5.0<\mathrm{D}\left(\mathrm{H}-\mathrm{C}_{2} \mathrm{H}\right) \leq 5.79 \mathrm{eV}$ as determined by thermodynamic cycles $[16,38]$, proton transfer [39, 40], dissociative ionization [32, 33], and spectroscopy [41-43]. One of the most reliable value is obtained by negative ion electron detachment spectroscopy [16], i.e. $5.69 \pm 0.03 \mathrm{eV}$. Using this value and $\operatorname{IE}\left(\mathrm{C}_{2} \mathrm{H}\right)$ $=11.6 \pm 0.5 \mathrm{eV}$, an appearance energy of $17.29 \pm 0.53 \mathrm{eV}$ is calculated and in excellent agreement with the result of the present work.

To make sure that the process measured at $17.3 \mathrm{eV}$ has to be ascribed only to the decomposition of $\mathrm{C}_{2} \mathrm{H}_{2}{ }^{+}$, the PIPECO spectrum has been measured and is shown in Fig. $6 \mathrm{~b}$. The onset for $\mathrm{C}_{2} \mathrm{H}^{+}$unequivocally lies at $17.35 \pm 0.04 \mathrm{eV}$, i.e. at the point where the vibrational structure of the $\mathrm{A}^{2} \mathrm{~A}_{\mathrm{g}}$ (or $\mathrm{A}^{2} \Sigma_{\mathrm{g}}^{+}$in $\mathrm{D}_{\infty}$ symmetry) of $\mathrm{C}_{2} \mathrm{H}_{2}{ }^{+}$is broadened and disappears (see Fig. 6a). This latter observation is a witness to the predissociation of the $\mathrm{A}^{2} \mathrm{~A}_{\mathrm{g}}$ state. On the other hand, Fig. $6 \mathrm{c}$ shows that the molecular ion does not survive to dissociative ionization above $17.7 \mathrm{eV}$. Finally, the present experiment being performed with $\mathrm{He}(\mathrm{I})$ radiation, the contribution of autoionization could almost be excluded. The result of the present work is in excellent agreement with the ZEKEPEPICO [34] and threshold PEPICO [35] works. In the latter experiments, autoionization phenomena could participate to the dissociative ionization. Furthermore, it has been shown experimentally [44] that no ion-pair producing process occurs at this energy. Both the reactions

$$
\mathrm{C}_{2} \mathrm{H}_{2}+\mathrm{e}^{-} \rightarrow \mathrm{C}_{2} \mathrm{H}^{+}\left(\mathrm{C}_{2} \mathrm{H}^{-}\right)+\mathrm{H}^{-}\left(\mathrm{H}^{+}\right)+\mathrm{e}^{-}
$$

have been investigated by recording the ionization efficiency curves and measuring the threshold energies for $\mathrm{C}_{2} \mathrm{H}^{-}$and $\mathrm{H}^{-}$. For the latter ion the threshold being at $18.0 \pm 0.1 \mathrm{eV}$ [44], this mechanism of production of $\mathrm{C}_{2} \mathrm{H}^{+}$ has also to be discarded as responsible for the signal observed below $17.3 \mathrm{eV}$. They could not be detected by PEPICO.

Finally the second appearance energy of $\mathrm{C}_{2} \mathrm{H}^{+}$as determined by electron impact, i.e. at $18.27 \pm 0.10 \mathrm{eV}$ in $\mathrm{C}_{2} \mathrm{H}_{2}$ and at $18.45 \pm 0.26 \mathrm{eV}$ in $\mathrm{C}_{2} \mathrm{D}_{2}$, corresponds remarkably well to the sharp increase in the PIPECO signal at the same energy (see Fig. 6b). This threshold correlates with the adiabatic ionization energy of $\mathrm{C}_{2} \mathrm{H}_{2}{ }^{+}$. This state is fully predissociated as shown by Fig. $6 \mathrm{c}$ by the absence of any $\mathrm{C}_{2} \mathrm{H}_{2}{ }^{+}$coincidence signal in the corresponding energy range. To interpret this onset it is likely to assign it to the reaction

$$
\begin{aligned}
\mathrm{C}_{2} \mathrm{H}_{2}+h v & \left(\mathrm{e}^{-}\right) \\
& \rightarrow \mathrm{C}_{2} \mathrm{H}_{2}^{+}\left(\mathrm{B}^{2} \Sigma_{\mathrm{u}}^{+}\right) \stackrel{\text { prediss }}{\stackrel{{ }^{4} \Sigma^{-}}{\longrightarrow}} \mathrm{C}_{2} \mathrm{H}^{+}\left(\mathrm{A}^{3} \Sigma^{-}\right)+\mathrm{H}\left({ }^{2} \mathrm{~S}_{\mathrm{g}}\right)+(2) \mathrm{e}^{-}
\end{aligned}
$$

where the $\mathrm{C}_{2} \mathrm{H}^{+}$ion should be in its first excited $\mathrm{A}^{3} \sum^{-}$state at $0.7-1.0 \mathrm{eV}$ above the ground vibronic state [23, 45 , 46]. 
The conclusions drawn from the foregoing discussion have been included in the schematic potential energy diagram along the $\mathrm{H}-\mathrm{C}_{2} \mathrm{H}$ reaction coordinate shown in Fig. 12.

\subsection{The $\mathrm{CH}^{+}\left(\mathrm{CD}^{+}\right)$dissociative ionization channel}

The lowest onset energy for $\mathrm{CH}^{+}$production is $20.83 \pm 0.05 \mathrm{eV}$, whereas for $\mathrm{CD}^{+}$it is measured at 20.61 $\pm 0.07 \mathrm{eV}$. The electron impact values reported in the literature scatter between $20.0 \pm 1.0 \mathrm{eV}$ [47] to $23.1 \mathrm{eV}$ [48]. By photoionization only one determination is reported at $20.7 \mathrm{keV}$ [32]. Initial $\mathrm{KE}$ of $50 \mathrm{meV}$ has been measured on $\mathrm{CH}^{+}$and no $\mathrm{KE}$ is observed on $\mathrm{CD}^{+}$. The $\mathrm{KE}$ versus $\mathrm{AE}$ diagram related to $\mathrm{CH}^{+}$and $\mathrm{CD}^{+}$are shown in Figs. 8 and 9. The straight line (1) and (1') correspond to the lowest energetic process. Both linear regressions are characterized by a correlation coefficient better than 0.99 . For $\mathrm{CH}^{+}$a slope and extrapolation to $\mathrm{KE}=0.0 \mathrm{eV}$ are $0.39 \pm 0.02$ and $20.85 \pm 0.05 \mathrm{eV}$. For the isotopic counterpart $\mathrm{CD}^{+}$the same quantities are $0.35 \pm 0.01$ and 20.47 $\pm 0.02 \mathrm{eV}$. Though at the limit of the estimated error, the experimental data related to $\mathrm{CD}^{+}$are systematically lower than those related to $\mathrm{CH}^{+}$. This displacement should be significant and have a physical meaning on the base of two arguments: (i) the very good correlation coefficients of straight line (1) (0.994) and (1') (0.999) and (ii) the full overlap of the data of $\mathrm{CH}^{+}$and $\mathrm{CD}^{+}$giving rise to line (2) in Fig. 9. Any systematic error on the first data set would have led to a comparable error of the same sign on the measurement of the second onset.

The production of $\mathrm{CH}^{+}$from $\mathrm{C}_{2} \mathrm{H}_{2}$ at the thermodynamic threshold should provide the fragments in their ground vibronic state through the reaction

$$
\mathrm{C}_{2} \mathrm{H}_{2}+\mathrm{e}^{-} \rightarrow \mathrm{CH}^{+}\left(\mathrm{X}^{\prime} \Sigma^{+}, v=0\right)+\mathrm{CH}\left(\mathrm{X}^{2} \Pi, v=0\right)+2 \mathrm{e}^{-}
$$

Considering the difference of $\mathrm{CH}^{+}$and $\mathrm{CD}^{+}$as significant, the lowest onset should be at $20.47 \pm 0.02 \mathrm{eV}$ for $\mathrm{KE}\left(\mathrm{CD}^{+}\right)=0.0 \mathrm{eV}$. Subtracting the ionization energy $(\mathrm{IE}(\mathrm{CH})=10.64 \mathrm{eV}$ (see Table 1$)$ the value $D(D C \equiv C D)=D(H C \equiv C H)=9.83 \pm 0.10 \mathrm{eV}$ is obtained. This identity is justified, the error being much larger than the expected isotope effect.

The dissociation energy thus obtained could be compared with earlier values. Thermodynamical calculations [49, 50] agree about a value of $9.97 \mathrm{eV}$. Ervin et al. [16] deduced an energy of $10.00 \pm 0.03 \mathrm{eV}$ from negative ion photoelectron spectroscopy. Herzberg [13] proposes $9.886 \mathrm{eV}$ as being the most reliable value. Theoretical calculations provide a dissociation energy of $9.826 \mathrm{eV}$. The present determination of $9.83 \pm 0.10 \mathrm{eV}$ fits in this set of values.

The production of ground state fragments should only be valid for $\mathrm{CD}^{+}$from $\mathrm{C}_{2} \mathrm{D}_{2}$ at $20.47 \mathrm{eV}$. For $\mathrm{CH}^{+}$ from $\mathrm{C}_{2} \mathrm{H}_{2}$, the energy difference of $20.83( \pm 0.08)-20.47( \pm 0.02)=0.36 \pm 0.10 \mathrm{eV}$ should be ascribed to the vibrational excitation of $\mathrm{CH}^{+}$or $\mathrm{CH}$, i.e. $\omega_{\mathrm{e}}\left(\mathrm{CH}^{+}\right)=0.339 \mathrm{eV}$ and $\omega_{\mathrm{e}}(\mathrm{CH})=0.354 \mathrm{eV}$ [14].

The straight lines (1) and (1') (see Figs. 7 and 8) are characterized by an identical slope of 0.39 . This is significantly different from the expected value of $13 / 26=0.500$. This is indicative of the partitioning of the excess energy between translational and internal energy carried by the fragments. For both $\mathrm{CH}^{+}$and $\mathrm{CD}^{+}$an energy balance could be made. Both fragments carry up to $0.5 \mathrm{eV}$ kinetic energy or $1.0 \mathrm{eV}$ in terms of total energy. Subtracting this quantity from the difference (21.90-20.47) eV (see Fig. 8), one obtains an excess energy of $0.4 \pm 0.1 \mathrm{eV}$ corresponding fairly well to two vibrational quanta of $\mathrm{CD}^{+}$or $\mathrm{CD}$, i.e. $\omega_{\mathrm{e}}\left(\mathrm{CD}^{+}\right)=0.251 \mathrm{eV}$ and $\omega_{\mathrm{c}}(\mathrm{CD})=0.260 \mathrm{eV}[14]$. Concerning $\mathrm{CH}^{+}$, likely produced in its $\left(\mathrm{X}^{1} \Sigma^{+}, v=1\right)$ level, the internal energy is estimated in the same way to be $0.25 \pm 0.1 \mathrm{eV}$ (see Fig. 7) which could fit only one quantum number of $\mathrm{CH}^{+}$or $\mathrm{CH}$ [14]. The detailed mechanism describing the production of $\mathrm{CH}^{+}$and $\mathrm{CD}^{+}$at their lowest onset should be through the reaction

$$
\begin{gathered}
\mathrm{C}_{2} \mathrm{H}_{2}\left(\mathrm{C}_{2} \mathrm{D}_{2}\right)+\mathrm{e}^{-} \rightarrow \mathrm{C}_{2} \mathrm{H}_{2}\left(\mathrm{C}_{2} \mathrm{D}_{2}\right) * \underset{\text { ioniz. }}{\stackrel{\text { auto }}{\longrightarrow}}\left[\mathrm{C}_{2} \mathrm{H}_{2}\left(\mathrm{C}_{2} \mathrm{D}_{2}\right)\right]^{+}\left(\mathrm{B}^{2} \Sigma_{\mathrm{u}}^{+}\right)+2 \mathrm{e}^{-} \\
\stackrel{\text { prediss }}{\underset{\mathrm{X}^{2} \Pi_{\mathrm{u}}}{\longrightarrow}} \mathrm{CH}^{+}\left(\mathrm{X}^{1} \Sigma^{+}, v=1 \rightarrow 2\right)+\mathrm{CH}\left(\mathrm{X}^{2} \Pi, v=0\right) \\
\stackrel{\text { prediss }}{\underset{\mathrm{X}^{2} \Pi_{\mathrm{u}}}{\longrightarrow}} \mathrm{CD}^{+}\left(\mathrm{X}^{1} \Sigma^{+}, v=0 \rightarrow 2\right)+\mathrm{CD}\left(\mathrm{X}^{2} \Pi, v=0\right)
\end{gathered}
$$

where the vibrational excitation could be equally transferred to $\mathrm{CH}(\mathrm{CD})$. In the above reaction scheme, ${ }^{1} \Sigma^{+}{ }_{-}^{2} \Pi$ fragments correlate with a ${ }^{2} \Pi$ molecular ion state. In the energy range to be considered the $\mathrm{C}_{2} \mathrm{H}_{2}^{+}\left(\mathrm{B}^{2} \Sigma_{\mathrm{u}}{ }^{+}\right)$state could be populated by autoionization (see Fig. 6a) and is predissociated by the continuum of the $X^{2} \Pi_{u}$ state. 
Only observed for $\mathrm{CD}^{+}$, the straight line (1") corresponds to an onset $\mathrm{AE}\left(\mathrm{CD}^{+}\right)_{\mathrm{KE}=0.0}=20.90 \pm 0.05 \mathrm{eV}$, in excellent agreement with the extrapolated value of $20.85 \pm 0.05 \mathrm{eV}$ for $\mathrm{CH}^{+}$. This would be a first argument favouring the assignment

$$
\mathrm{C}_{2} \mathrm{D}_{2}+\mathrm{e}^{-} \rightarrow \mathrm{CD}^{+}\left(\mathrm{X}^{1} \Sigma^{+}, v\right)+\mathrm{CD}\left(\mathrm{X}^{2} \Pi, v=0\right)+2 \mathrm{e}^{-}
$$

to this threshold. A second experimental evidence supporting this interpretation is the slope on the linear fit (1"), i.e. $s^{i}=0.224 \pm 0.004$ with a correlation coefficient of 0.999 . The corresponding slope in $\mathrm{CH}^{+}$is $s=0.39 \pm 0.02$. The isotope effect on the vibrational energy can be predicted by determining the ratio $\varrho=\left(\omega_{\mathrm{e}}{ }^{\mathrm{i}} / \omega_{\mathrm{e}}\right)^{2}[52]$ which has been shown to be given by $s^{\mathrm{i}} / s[20]$. In the present case

$$
s^{i} / s=0.57 \pm 0.04 ; Q^{\text {ion }}=0.54 ; Q^{\text {neutral }}=0.55
$$

Though the good agreement between experiment and predictions, it is not allowed to decide whether $\mathrm{CD}$ and/or $\mathrm{CD}^{+}$are excited. Furthermore, from a simple energy balance in $\mathrm{C}_{2} \mathrm{D}_{2}$, between 20.9 and $23.2 \mathrm{eV}$ the dissociation process is

$$
\mathrm{C}_{2} \mathrm{D}_{2}+\mathrm{e}^{-} \rightarrow \mathrm{CD}^{+}\left(\mathrm{X}^{1} \Sigma^{+}, v=1,2 \rightarrow 6,7\right)+\mathrm{CD}\left(\mathrm{X}^{2} \Pi, v=0\right)+2 \mathrm{e}^{-}
$$

Straight line (2) in Figs. 8 and 9 has a slope of $0.52 \pm 0.02$ and extrapolates to $\mathrm{KE}=0.0 \mathrm{eV}$ at $21.23 \pm 0.04 \mathrm{eV}$ for $\mathrm{CH}^{+}$and at $21.18 \pm 0.07 \mathrm{eV}$ for $\mathrm{CD}^{+}$. The most obvious interpretation of this onset would be

$$
\begin{gathered}
\mathrm{C}_{2} \mathrm{H}_{2}+\mathrm{e}^{-} \rightarrow \mathrm{C}_{2} \mathrm{H}_{2}^{*} \underset{\text { ioniz. }}{\stackrel{\text { auto }}{\longrightarrow}} \mathrm{C}_{2} \mathrm{H}_{2}^{+}\left(\mathrm{B}^{2} \Sigma_{\mathrm{u}}^{+}\right)+2 \mathrm{e}^{-} \\
\stackrel{\text { prediss }}{\longrightarrow} \mathrm{CH}^{+}\left(X^{1} \Sigma, v=0\right)+\mathrm{CH}\left(\mathrm{a}^{4} \Sigma^{-}, v=0\right)
\end{gathered}
$$

where the $\mathrm{CH}$ radical is produced in its first electronic excited state at $0.724 \mathrm{eV}$ above the ground state (see Table 1). This spectroscopic value has to be compared with the energy difference of $0.73 \pm 0.12 \mathrm{eV}$ determined in this work. The total excess energy is converted in translational energy carried by the fragments. This reaction has to run over a $\mathrm{C}_{2} \mathrm{H}_{2}$ autoionizing state identified at $21.0 \mathrm{eV}$ in the threshold photoelectron spectrum [11]. Autoionization is allowed to the nearest $\mathrm{B}^{2} \Sigma_{\mathrm{u}}{ }^{+}$ionization continuum. This state would be predissociated by a ${ }^{4} \Sigma$ state, the only ionic state correlating with both fragments.

At $21.8 \pm 0.1 \mathrm{eV}$ straight line (3) is characterized by a slope of $0.30 \pm 0.02$ for $\mathrm{CH}^{+}$and $0.26 \pm 0.02$ for $\mathrm{CD}^{+}$. The energy difference of $21.8( \pm 0.1)-20.5( \pm 0.08)=1.3 \pm 0.18 \mathrm{eV}$ could be accounted for by the electronic excitation of $\mathrm{CH}^{+}$in its $\mathrm{a}^{3} \prod$ state. By optical spectroscopy this energy interval is $1.141 \mathrm{eV}$ (see Table 1). The most straightforward assignment would be the mechanism 8

$$
\mathrm{C}_{2} \mathrm{H}_{2}+\mathrm{e}^{--} \mathrm{C}_{2} \mathrm{H}_{2}^{*} / \mathrm{C}_{2} \mathrm{H}_{2}^{+}\left(\mathrm{C}^{2} \Sigma_{\mathrm{g}}^{+}\right) \stackrel{\text { prediss }}{\longrightarrow} \mathrm{CH}^{+}\left(\mathrm{a}^{3} \Pi\right)+\mathrm{CH}\left(\mathrm{X}^{2} \Pi\right)+2 \mathrm{e}^{-} \text {. }
$$

Both fragments correlate with doublet and quartet $\Sigma$ and $A$ states. On the basis of the usual selection rules and Hund's rule [52] a ${ }^{4} \Sigma$ would be expected to be involved in (8). Both the Rydberg state at $21.5 \mathrm{eV}$ and the ionic state at $23.5 \mathrm{eV}[11,28,29]$ are predissociated.

The same reaction (8) would account for the $\mathrm{CH}^{+}$ions observed between $22 \mathrm{eV}$ and $25 \mathrm{eV}$ and for which the data correspond to the straight line (5) extrapolating to $21.8 \pm 0.12 \mathrm{eV}$. The same intermediate states are involved. However, the predissociating state would be a ${ }^{2} \Sigma$ state, lying above the ${ }^{4} \Sigma$ state, but correlated to the same reaction products.

The above discussed reaction mechanisms have been schematically drawn in a potential energy diagram displayed in Fig. 12 along the $\mathrm{HC} \equiv \mathrm{CH}$ reaction coordinate.

The data fitting the straight line (4) give rise to $\mathrm{AE}\left(\mathrm{CH}^{+}\right)_{\mathrm{KE}=0.0}=22.6 \pm 0.1 \mathrm{eV}$ and the slope is 0.53 \pm 0.03 . The extrapolation energy is in fairly good agreement with the thermodynamic onset calculated for 


$$
\mathrm{C}_{2} \mathrm{H}_{2}+\mathrm{e}^{-} \rightarrow \mathrm{C}_{2} \mathrm{H}_{2}^{+}\left(\mathrm{C}_{2} \Sigma_{\mathrm{g}}^{+}\right) \stackrel{\text { prediss }}{\underset{{ }^{2} \Pi}{\longrightarrow}} \mathrm{CH}^{+}\left(\mathrm{a}^{3} \Pi\right)+\mathrm{CH}\left(\mathrm{a}^{4} \Sigma^{-}\right)+2 \mathrm{e}^{-}
$$

at $22.35 \pm 0.10 \mathrm{eV}$ (see Table 1). The reaction would occur through the $\mathrm{C}^{2} \Sigma_{\mathrm{g}}^{+}$hypersurface predissociated by a ${ }^{2} \Pi$ which correlate with both fragments in their first electronic excited state.

The appearance energies of $\mathrm{CH}^{+}$observed above $26 \mathrm{eV}$ are difficult to assign unequivocally to well defined processes. Several mechanisms are predicted to occur in a fairly narrow energy band (data from Table 1). Both $\mathrm{CH}^{+}$and $\mathrm{CH}$ could be excited to higher electronic states and/or can dissociate. In the energy range of 26-29 eV, X-ray valence-excitation photoelectron spectroscopy shows the existence of a number of dissociative ${ }^{2} \Sigma$ states [29, 30] likely involved in the dissociative ionization processes considered in this energy range.

Above an energy gap of about $5 \mathrm{eV}$, up from $34 \mathrm{eV}, \mathrm{CH}^{+}$ions are essentially produced with large amounts of translational energy. This energy range corresponds to that of the double ionization energy continuum of $\mathrm{C}_{2} \mathrm{H}_{2}$. At $33.8 \mathrm{eV}$ the $\mathrm{CH}^{+}$ion carries 1.4-3.5 eV kinetic energy. The energy balance with these data leads to $\mathrm{AE}\left(\mathrm{CH}^{+}\right)_{\mathrm{KE}=0.0}=26.8 \pm 0.3 \mathrm{eV}$. This is well below the first double ionization energy of $\mathrm{C}_{2} \mathrm{H}_{2}$, measured at $32.2 \mathrm{eV}$ [1], and the thermodynamic onset calculated at $31.1 \pm 0.1 \mathrm{eV}$ for the reaction

$$
\mathrm{C}_{2} \mathrm{H}_{2}+\mathrm{e}^{-} \rightarrow 2 \mathrm{CH}^{+}\left(\mathrm{X}^{+} \Sigma^{+}\right)+3 \mathrm{e}^{-}
$$

Probably an intermediate $\mathrm{C}_{2} \mathrm{H}_{2}{ }^{+} *$ state is involved, lying in the double ionization continuum.

Between 36-42 eV two onsets are measured at $36.2 \pm 0.5 \mathrm{eV}$ and at $38.5 \pm 0.6 \mathrm{eV}$ respectively. The former threshold is related to the reaction 10 where the products correlate with the only $\mathrm{C}_{2} \mathrm{H}^{2+}\left({ }^{1} \Sigma^{+}\right)$state. An energy balance on this onset provides $\mathrm{AE}\left(\mathrm{CH}^{+}\right)_{\mathrm{KE}=0.0}=31.4 \pm 0.5 \mathrm{eV}$, in good agreement with the predicted onset for reaction 10 at $31.1 \pm 0.1 \mathrm{eV}$. Finally the process at $38.5 \pm 0.6 \mathrm{eV}$ could be ascribed to

$$
\mathrm{C}_{2} \mathrm{H}_{2}+\mathrm{e}^{-} \rightarrow \mathrm{CH}^{+}\left(\mathrm{X}^{1} \Sigma^{+}\right)+\mathrm{CH}^{+}\left(\mathrm{a}^{3} \Pi\right)+3 \mathrm{e}^{-}
$$

for which the thermodynamic onset is calculated at $32.24 \pm 0.10 \mathrm{eV}$. No doubly ionized $\mathrm{C}_{2} \mathrm{H}_{2}$ state has been observed experimentally in this energy range. However, quantum mechanical calculations predict ${ }^{3} \Pi$ states in this range [53]. These are very likely unstable in the Franck-Condon region.

\subsection{The $\mathrm{C}^{+}, \mathrm{C}_{2}^{+}$and $\mathrm{CH}_{2}^{+}$dissociation channels}

\subsection{1}

As shown in Fig. 10, at low electron energy the $\mathrm{C}^{+}$ions are produced with small amounts of kinetic energy whereas they carry large translational energies above $26 \mathrm{eV}$. The lowest threshold of $\mathrm{C}^{+}$is measured at $21.16 \pm 0.3 \mathrm{eV}$ and is difficult to compare with the broadly scattering values reported in the literature $[18,36,48]$. The first thermodynamical onset is calculated at $20.22 \pm 0.10 \mathrm{eV}$ for the reaction

$$
\mathrm{C}_{2} \mathrm{H}_{2}+\mathrm{e}^{-} \rightarrow \mathrm{C}^{+}\left({ }^{2} \mathrm{P}_{\mathrm{u}}\right)+\mathrm{CH}_{2}\left(\mathrm{X}^{3} \Sigma_{\mathrm{g}}^{-}\right)+2 \mathrm{e}^{-}
$$

which is about $1 \mathrm{eV}$ below the present experimental determination. However, the $\mathrm{CH}_{2}$ radical is characterized by its $\mathrm{a}^{1} \mathrm{~A}_{1}$ and $\mathrm{b}^{1} \mathrm{~B}_{1}$ states at $0.4 \mathrm{eV}$ and $1.3 \mathrm{eV}[13,54]$ respectively above its ground state. The suggested reaction mechanism at $21.16 \mathrm{eV}$ is

$$
\mathrm{C}_{2} \mathrm{H}_{2}+\mathrm{e}^{-} \underset{\text { isomer }}{\stackrel{\text { autonion }}{\longrightarrow}}\left[\mathrm{H}_{2} \mathrm{C}=\mathrm{C}^{+},{ }^{2} \mathrm{~A}_{1}\right] \rightarrow \mathrm{C}^{+}\left({ }^{2} \mathrm{P}_{\mathrm{u}}\right)+\mathrm{CH}_{2}\left(\mathrm{a}^{1} \mathrm{~A}_{1}, v^{*}\right)+2 \mathrm{e}^{-}
$$

where $\mathrm{CH}_{2}$ carries internal energy to account for the slope of 0.38 of straight line (1). This reaction has to occur (i) through autoionization of the Rydberg state at $21.5 \mathrm{eV}$ [11] and (ii) over an isomerisation mechanism involving the vinylidene structure of the ion.

The onsets (2) and (3) at $22.4 \pm 0.2 \mathrm{eV}$ and $23.65 \pm 0.13 \mathrm{eV}$ are also defined by a restricted number of data points (see Fig. 10). In both cases the slope of the respective straight lines are significantly lower than the predicted $14 / 26=0.54$ value. An excess energy of $22.24-20.22=2.02 \pm 0.3 \mathrm{eV}$ is measured for (2) and the reaction 


$$
\mathrm{C}_{2} \mathrm{H}_{2}+\mathrm{e}^{-} \underset{\text { isomer }}{\stackrel{\mathrm{C}^{2} \Sigma_{\mathrm{g}}^{+}}{\longrightarrow}}\left[\mathrm{H}_{2} \mathrm{C} \equiv \mathrm{C}^{+}\right] \rightarrow \mathrm{C}^{+}\left({ }^{2} \mathrm{P}_{\mathrm{u}}\right)+\mathrm{CH}_{2}\left(\mathrm{~b}^{1} \mathrm{~B}_{1}, v^{*}\right)+2 \mathrm{e}^{-}
$$

could be invoked for the assignment. It should occur at the expense of the $\mathrm{C}_{2} \mathrm{H}_{2}{ }^{+}\left(\mathrm{C}^{2} \Sigma_{\mathrm{g}}{ }^{+}\right)$state. The energy difference of 23.65-20.22 $=3.43 \pm 0.23 \mathrm{eV}$ could be accounted for by

$$
\mathrm{C}_{2} \mathrm{H}_{2}+\mathrm{e}^{-} \rightarrow \mathrm{C}^{+}\left({ }^{2} \mathrm{P}_{\mathrm{u}}\right)+\mathrm{C}\left({ }^{3} \mathrm{P}_{\mathrm{g}}\right)+\mathrm{H}_{2}\left(\mathrm{X}^{1} \Sigma_{\mathrm{g}}^{+}, \nu^{*}\right)+2 \mathrm{e}^{-}
$$

calculated at $23.53 \pm 0.20 \mathrm{eV}$ and where $\mathrm{H}_{2}$ carries excess internal energy.

Above $26 \mathrm{eV}$ electron energy onsets are observed at $26.45 \pm 0.10 \mathrm{eV}, 28.5 \pm 0.3 \mathrm{eV}$ and $29.7 \pm 0.10 \mathrm{eV}$. By linear regression extrapolations to $\mathrm{KE}\left(\mathrm{C}^{+}\right)=0.0 \mathrm{eV}$ are obtained at $25.38 \pm 0.20 \mathrm{eV}, 27.42 \pm 0.20 \mathrm{eV}$ and $28.76 \pm 0.12$ $\mathrm{eV}$ respectively. The slope of the straight lines (4)-(7) is 0.38 . Consequently, the corresponding processes involve vibrational excitation of a di(poly)atomic fragment. For onsets (4) and (5) the processes could be

$$
\mathrm{C}_{2} \mathrm{H}_{2}+\mathrm{e}^{-} \rightarrow \mathrm{C}^{+}\left({ }^{2} \mathrm{P}_{\mathrm{u}}\right)+\mathrm{H}\left({ }^{2} \mathrm{~S}_{\mathrm{g}}\right)+\mathrm{CH}\left(\mathrm{a}^{4} \Sigma^{-} / \mathrm{A}^{2} \Delta, v^{*}\right)+2 \mathrm{e}^{-}
$$

for which the onset is calculated at $25.32 \pm 0.20 \mathrm{eV}$ and $27.44 \pm 0.20 \mathrm{eV}$ respectively. For the onset detected at 29.7 $\mathrm{eV}$ and extrapolating to $28.8 \mathrm{eV}$, the mechanism (18) should require $28.9 \mathrm{eV}$ comparing satisfactorily with the experimental value of $28.76 \pm 0.12 \mathrm{eV}$

$$
\mathrm{C}_{2} \mathrm{H}_{2}+\mathrm{e}^{-} \rightarrow \mathrm{C}^{+}\left({ }^{4} \mathrm{P}_{\mathrm{u}}\right)+\mathrm{C}\left({ }^{3} \mathrm{P}_{\mathrm{g}}\right)+\mathrm{H}_{2}\left(\mathrm{X}^{1} \Sigma_{\mathrm{g}}^{+}, \nu^{*}\right)+2 \mathrm{e}^{-} .
$$

The fragmentation pattern of $\mathrm{C}_{2} \mathrm{H}_{2}$ in this energy range does not necessarily involve the vinylidenic structure of $\mathrm{C}_{2} \mathrm{H}_{2}{ }^{+}$as a transient. However, as in the previously discussed dissociation channels, the dissociative ${ }^{2} \Sigma^{+}$ionic states detected in the X-ray valence-shell photoelectron spectrum $[29,30]$ would play an essential role.

\subsection{2}

The $\mathrm{C}_{2}{ }^{+}$dissociation channel is open at $18.44 \pm 0.07 \mathrm{eV}$. This is in rather good agreement with previous electron impact works [18, 36, 47, 48]. By photoionization [32] the onset is determined at $18.16 \mathrm{eV}$. The calculation of the thermodynamical onset for $\mathrm{C}_{2}^{+}$production through the reaction (19), i.e.

$$
\mathrm{C}_{2} \mathrm{H}_{2}+\mathrm{e}^{-} \rightarrow \mathrm{C}_{2} \mathrm{H}_{2}^{+}\left(\mathrm{B}^{2} \Sigma_{\mathrm{u}}^{+}\right) \underset{\text { prediss }}{\stackrel{\text { isomer }}{\longrightarrow}} \mathrm{C}_{2}^{+}\left(\mathrm{X}^{4} \Sigma_{\mathrm{g}}^{-}\right)+\mathrm{H}_{2}\left(\mathrm{X}^{1} \Sigma_{\mathrm{g}}^{+}\right)+2 \mathrm{e}^{-}
$$

involves the value of the $\mathrm{H}-\mathrm{C}_{2}$ binding energy. Using the data of Table 1 and assuming the $\mathrm{C}_{2}{ }^{+}$ion carrying no kinetic energy, a value of $D\left(H-C_{2}\right)=5.44 \pm 0.4 \mathrm{eV}$ is obtained. By other experimental methods $5.20 \mathrm{eV}$ and 5.11 $\pm 0.11 \mathrm{eV}$ are proposed [12, 16, 37]. By theoretical calculations $4.86 \mathrm{eV}$ is obtained [56]. The present electron impact value is very likely overestimated, owing to the shape of the ionization efficiency curve in the threshold region.

The onset of $18.44 \mathrm{eV}$ corresponding very well to the ionization energy of the $2 \sigma_{\mathrm{u}}$ orbital, the dissociation mechanism is probably a predissociation of the $\mathrm{C}_{2} \mathrm{H}_{2}{ }^{+}\left(\mathrm{B}^{2} \Sigma_{\mathrm{u}}{ }^{+}\right)$state (see Fig. 6a). It should occur after isomerisation of the molecular ion into its vinylidenic structure. $\mathrm{A}^{4} \mathrm{~B}_{2}$ state, as derived from the ${ }^{4} \Sigma_{\mathrm{g}}{ }^{-}$state, should be the predissociating state.

At $19.58 \pm 0.14 \mathrm{eV}$ the second $\mathrm{C}_{2}{ }^{+}$threshold is measured. The excess energy of $1.14 \pm 0.18 \mathrm{eV}$ has to be ascribed very likely to the electronic excitation of $\mathrm{C}_{2}{ }^{+}$in the $\mathrm{a}^{2} \Pi_{\mathrm{u}}$ or $\mathrm{A}^{4} \Pi_{\mathrm{g}}$ state. These are calculated at $0.82 \mathrm{eV}$ and $1.3 \mathrm{eV}$ above the ground state [57, 58]. The energy level of $19.58 \mathrm{eV}$ still lies in the $\mathrm{B}^{2} \Sigma_{\mathrm{u}}^{+}$state energy range, but corresponds to the end of the vibrational structure of this state (see Fig. 6a).

To the threshold at $23.00 \pm 0.12 \mathrm{eV}$ corresponds an important increase of the ionization efficiency. The energy difference of $23.00-18.44=4.56 \pm 0.18 \mathrm{eV}$ has very probably to be assigned to the dissociation of $\mathrm{H}_{2}$ which requires $4.476 \mathrm{eV}$ (see Table 1). At this energy the reaction

$$
\mathrm{C}_{2} \mathrm{H}_{2}+\mathrm{e}^{-} \rightarrow \mathrm{C}_{2} \mathrm{H}_{2}^{+}\left(\mathrm{C}^{2} \Sigma_{\mathrm{g}}^{+}\right) \stackrel{\text { prediss }}{\underset{{ }^{\Sigma} \Sigma}{\mathrm{L}}} \mathrm{C}_{2}^{+}\left(\mathrm{X}^{4} \Sigma_{\mathrm{g}}^{-}\right)+2 \mathrm{H}\left({ }^{1} \mathrm{~S}_{\mathrm{g}}\right)+2 \mathrm{e}^{-}
$$


should take place and its onset energy lies in the energy range of the $\mathrm{C}_{2} \mathrm{H}_{2}^{+}\left(\mathrm{C}^{2} \Sigma_{\mathrm{g}}^{+}\right)$state which has to be predissociated by a ${ }^{4} \Sigma$ state correlating with the fragments.

\section{3 .3}

For the reasons already mentioned, the $\mathrm{CH}_{2}{ }^{+}$ion is only investigated below $24.3 \mathrm{eV}$. The onsets above this level correspond to the $\mathrm{N}^{+}$production from $\mathrm{N}_{2}$ [9].

The first onset for $\mathrm{CH}_{2}{ }^{+}$production is determined at $19.74 \pm 0.20 \mathrm{eV}$ (see Fig. 11). The experimental data fit a straight line (1) with a slope of $0.45 \pm 0.02$. It has to be compared to the predicted value of $12 / 26=0.46$. The thermodynamical onset for

$$
\mathrm{C}_{2} \mathrm{H}_{2}+\mathrm{e}^{-} \stackrel{\text { ioniz }}{\longrightarrow} \mathrm{C}_{2} \mathrm{H}_{2}^{+}\left(\mathrm{B}^{2} \Sigma_{\mathrm{u}}^{+}\right) \underset{\text { prediss }}{\stackrel{\text { isomer }}{\longrightarrow}} \mathrm{CH}_{2}^{+}\left(\mathrm{X}^{2} \mathrm{~B}_{1}\right)+\mathrm{C}\left({ }^{3} \mathrm{P}_{\mathrm{g}}\right)+2 \mathrm{e}^{-}
$$

is calculated at $19.36 \pm 0.10 \mathrm{eV}$. The discrepancy between experimental and predicted onset would be ascribed to the slow increase of the ionization efficiency a threshold. Hayaishi et al. [32] reported an appearance energy of $19.4 \mathrm{eV}$. Their photoionization efficiency curve shows a long tailing portion at the onset. Very likely the $\mathrm{C}_{2} \mathrm{H}_{2}{ }^{+}$ $\left(\mathrm{B}^{2} \Sigma_{\mathrm{u}}{ }^{+}\right)$state is involved in this reaction (see Fig. 6a). This state should isomerize to the vinylidene structure before it predissociates through a ${ }^{2} A_{1}$ or a ${ }^{2} \mathrm{~B}_{2}$ state.

The second appearance energy of $\mathrm{CH}_{2}{ }^{+}$is detected at $21.1 \pm 0.1 \mathrm{eV}$ and corresponds to straight line (2). The energy difference of $21.1-19.4=1.4 \pm 0.4 \mathrm{eV}$ could probably be assigned to the electronic excitation of the $\mathrm{C}$ atom in its ${ }^{1} \mathrm{D}_{\mathrm{g}}$ level at $1.264 \mathrm{eV}$ above the ground level. The $\mathrm{CH}_{2}{ }^{+}$ion producing reaction at this energy should be

$$
\mathrm{C}_{2} \mathrm{H}_{2}+\mathrm{e}^{-} \rightarrow \mathrm{C}_{2} \mathrm{H}_{2}^{*} \underset{\text { isomer }}{\stackrel{\text { autoion }}{\longrightarrow}} \mathrm{CH}_{2}^{+}\left(\mathrm{X}^{2} \mathrm{~B}_{1}\right)+\mathrm{C}\left({ }^{1} \mathrm{D}_{\mathrm{g}}\right)+2 \mathrm{e}^{-}
$$

where the Rydberg state at $23 \mathrm{eV}$ participate in this reaction.

\section{Acknowledgments}

We are indebted to the Université de Liège, the Fonds National de la Recherche Scientifique (FNRS) and the Fonds de la Recherche Fondamentale Collective (FRFC) for financial support.

\section{References}

1. M. Davister and R. Locht, Chem. Phys. 189 (1994) 805 and references therein.

2. R. Locht and J. Schopman, Intern. J. Mass Spectrom. Ion Phys. 15 (1974) 361.

3. Ch. Servais and R. Locht, Intern. J. Mass Spectrom. Ion Processes, to be published.

4. I. Lindau, J. C. Helmer and J. Uebbing, Rev. Sci. Instrum. 44 (1973) 265.

5. A. Lofthus and P. H. Krupenie, J. Phys. Chem. Ref. Data 6 (1977) 113.

6. C. E. Moore, Ionization potentials and ionization limits derived from the analyses of optical spectra, NSRDS-NBS 34 (1970).

7. J. E. Reutt, L. S. Wang, J. E. Pollard, D. J. Trevor, Y. T. Lee and D. A. Shirley, J. Chem. Phys. 84 (1986) 3022.

8. J. N. Miller, Spectrosc. Intern. 3(3) (1991) 42; 3(4) (1991) 41 ; 3(5) (1991) 43

9. R. Locht, J. Schopman, H. Wankenne and J. Momigny, Chem. Phys. 7 (1975) 393.

10. R. G. Cavell and D. A. Allison, J. Chem. Phys. 69 (1978) 159.

11. R. Locht, K. Hottmann and H. Baumgartel, to be published. 
Published in: Clinical Cancer Research: Zeitschrift für Physikalische Chemie (1996), . Bd. 195, pp. S. 153-179

Status: Postprint (Author's version)

12. R. S. Urdahl, Y. Bao and W. H. Jackson, Chem. Phys. Letters 178 (1991) 425.

13. G. Herzberg, Molecular spectra and molecular structure. Vol. 3. Electronic spectra of polyatomic molecules (Van Nostrand, Princeton 1967)

14. K. P. Huber and G. Herzberg, Molecular spectra and molecular structure. Vol. 4. Constants of diatomic molecules (Van Nostrand Reinhold, New York 1979).

15. H. Hotop and W. C. Lineberger; J. Phys. Chem. Ref. Data 14 (1985) 731.

16. K. M. Ervin, S. Gronert, S. E. Barlow, M. K. Gilles, A. G. Harrison, V. M. Bierbaum, C. H. DePuy, W. C. Lineberger and G. B. Ellison, J. Am. Chem. Soc. 112 (1990) 5750.

17. C. E. Moore, Atomic energy levels. Vol. 1. NSRDS-NBS Circ. 467 (USGPO, Washington D.C. 1949).

18. P. Kusch, A. Hustrulid and J. T. Tate, Phys. Rev. 52 (1937) 843.

19. H. Shiromura, Y. Achiba, K. Kimura and Y. T. Lee, J. Phys. Chem. 91 (1987) 17.

20. R. Locht, J. L. Olivier and J. Momigny, Chem. Phys. 43 (1979) 425.

21. S. Shih, S. D. Peyerimhoff and R. J. Buenker, J. Mol. Spectrosc. 64 (1977) 167.

22. S. Shih and S. D. Peyerimhoff, J. Mol. Spectrosc. 74 (1979) 124.

23. A. G. Koures and L. B. Harding, J. Phys. Chem. 95 (1991) 1035.

24. P. G. Carrick, A. J. Merer and R. F. Curl Jr., J. Chem. Phys. 78 (1983) 3652.

25. R. F. Curl Jr., P. G. Carrick and A. J. Merer, J. Chem. Phys. 83 (1985) 4278.

26. E. Somè, F. Remy, D. Macau-Hercot, I. Dubois, J. Breton and H. Bredohl, accepted in J. Mol. Spectrosc. (1995).

27. W. R. Graham, K. I. Dismuke and W. Weltner, J. Chem. Phys. 60 (1974) 3817.

28. G. Bieri and L. Åsbrink, J. Electron. Spectrosc. Relat. Phenom. 20 (1980) 149.

29. S. Svensson, E. Zdansky, U. Gelius and H. Ågren, Phys. Rev. A37 (1988) 4730

30. J. Muller, R. Arneberg, H. Ågren, R. Manne, P. Å. Mannquist, S. Svensson and U. Gelius, J. Chem. Phys. 77 (1982) 4895.

31. S. R. Andrews, F. M. Harris and D. E. Parry, Chem. Phys. 166 (1992) 69.

32. T. Hayaishi, S. Iwata, M. Sasanuma, E. Ishiguro, Y. Morioka, Y. Iida and M. Nakamu-ra, J. Phys. B15 (1982) 79.

33. Y. Ono and C. Y Ng, J. Chem. Phys. 74 (1981) 6985.

34. K. M. Weitzel, J. Mähnert and M. Penno, Chem. Phys. Letters 224 (1994) 371.

35. K. Norwood and C. Y. Ng, J. Chem. Phys. 91 (1989) 2898.

36. P. Plessis and P. Marmet, Int. J. Mass Spectrom. Ion Processes 70 (1986) 23.

37. J. R. Wyatt and F. E. Stafford, J. Phys. Chem. 76 (1972) 1913.

38. B. K. Janousek and J. I. Braunian, J. Chem. Phys. 71 (1979) 2057.

39. M. Iraqi, A. Petrank, M. Peres and C. Lifshitz, Int. J. Mass Spectrom. Ion Processes 100 (1990) 679.

40. I. Dotan, M. Iraqi and C. Lifshitz, Int. J. Mass Spectrom. Ion Processes 124 (1993) R21.

41. P. G. Green, J. L. Kinsey and R. W. Field, J. Chem. Phys. 91 (1989) 5160.

42. Y. Chen, D. M. Jonas, C. E. Hamilton, P. G. Green, J. L. Kinsey and R. W. Field, Ber. Bunsenges. Phys. Chem. 92 (1983) 329.

43. M. Fuji, A. Haijima and M. Ito, Chem. Phys. Letters 150 (1988) 380. 
Published in: Clinical Cancer Research: Zeitschrift für Physikalische Chemie (1996), . Bd. 195, pp. S. $153-179$

Status: Postprint (Author's version)

44. R. Locht and J. Momigny, Chem. Phys. Letters 6 (1970) 273.

45. A. O'Keefe, R. Derai and M. T. Bowers, Chem. Phys. 91 (1984) 161.

46. W. Koch and G. Frenking, J. Chem. Phys. 93 (1990) 8021.

47. G. Cooper, T. Ibuki, Y. Iida and C. E. Brion, Chem. Phys. 125 (1988) 307.

48. J. Momigny and E. Derouane, Adv. Mass Spectrom. 4 (1967) 607.

49. S. W. Benson, J. Chem. Educat. 42 (1965) 502.

50. T. L. Cottrell, The strength of chemical bonds (Butterworth, 1958).

51. S. R. Langhoff, C. W. Bauschlicher and P. R. Taylor, Chem. Phys. Letters 180 (1991) 88

52. G. Herzberg, Molecular spectra and molecular structure. Vol. 2. Spectra of diatomic molecules. (Von Nostrand, Princeton 1967).

53. R. Thissen, Ph. D. Thesis, Université de Liège (1992).

54. I. Shavitt, Tetrahedron 41 (1985) 1531.

55. P. Rosmus, P. Botschwina and J. P. Maier, Chem. Phys. Letters 84 (1981) 71.

56. C. W. Bauschlicher and S. R. Langhoff, Chem. Phys. Letters 173 (1990) 367.

57. C. Petrongolo, P. G. Bruna, S. D. Peyerimhoff and R. J. Buenker, J. Chem. Phys. 74 (1981) 4594.

58. P. Rosmus, H. J. Werner, E. A. Reinsch and M. Larsson, J. Electron Spectrosc. Relat. Phenom. 41 (1986) 289. 